\title{
Effect of Lateral Thinking Dispositions on Groupwork
}

\author{
Şenel Elaldı ${ }^{*}$ \\ ${ }^{1}$ Cumhuriyet University Education Faculty, Sivas, 58140, TURKEY \\ *Corresponding Author
}

DOI: https://doi.org/10.30880/jtet.2021.13.02.008

Received 16 ${ }^{\text {th }}$ June 2020; Accepted $10^{\text {th }}$ March 2021; Available online $30^{\text {th }}$ June 2021

\begin{abstract}
The aim of this study is to compare the effect of lateral thinking dispositions on groupwork in a collaborative learning environment from different angles as quantitatively and qualitatively in line with methodological pluralism. The population of the study included freshmen students studying Gastronomy and Culinary Arts in Tourism Faculty of a state university. The study was conducted in three samples within the scope of methodological pluralism including data triangulation (for SPSS analysis: $\mathrm{N}=83$ - all the students in the study universe-; for thematic analysis: $\mathrm{N}=66$ - selected on a voluntary basis depending on voluntary response sampling-; and for the Rasch analysis: N=16 students accepting to participate this aspect of the study voluntarily and 3 faculty members who have the responsibilities of the groupwork of the students). In the quantitative phase, descriptive analysis was performed through the Rasch Measurement Model and SPSS program while in the qualitative part of the study, the case study approach was conducted under the checklist of COREQ Statement. Rasch results indicated the LATD (Lateral Thinking Dispositions) scores of the students graduating from tourism or cooking related vocational high schools and having work experience were higher than their counterparts not graduating from tourism related high schools and had no work experience beforehand. Qualitative results showed consistency with the quantitative results. Teachers are suggested to be trained so that lateral thinking skills can be implemented in class environment.
\end{abstract}

Keywords: Culinary arts students, rasch model, thematic analysis, maxqda program, methodological pluralism, COREQ

\section{Introduction}

In recent years, culinary education has become popular with the emergence of media channels that increase celebrity chefs and draw attention to dining out (Johnston, \& Baumann, 2015). However, despite the increased enrolment in culinary programs today, outcomes emerging related to educational quality of some schools that have glorified advertisements have reflected inadequacy of the programs (Hertzman, \& Maas, 2012). It is clear that inefficient programs affect the quality of education negatively (Zopiatis, Theodosiou, \& Constanti, 2014). Therefore, it is expected culinary programs to guide educators to better prepare their students for their lifelong careers in the tourism industry. Since the industry seeks highly trained students to become skilled cooks and chefs of the future (Müller, Wan Leeuwen, Mandabach, \& Harrington, 2009).

Culinary programs focus on developing individuals with a familiarity or mastery of a wide assortment of cuisines and culinary techniques (Aud, Hussar, Kena, Bianco, Frohlich, \& Tahan, 2011). The goal is to raise gastronomy experts who are prone to team work, and can orient themselves to developing technology and learn latest advance cooking techniques (Moeller, \& Reitzes, 2011). Therefore, these programs provide students with individual and creative skills, knowledge and qualifications to take their business to the higher level in an academic environment. Training includes recipe development and menu planning, the preparation, cooking and aesthetics presentation of foods, an understanding of a wide-ranging variety of cuisines and culinary techniques, food purchasing and inventory management, and the supervision and training of kitchen staff (Choy, 2002). 
Culinary students matriculate in culinary education institutions with the expectations of attaining the experience and skills considered necessary to be successful in a culinary career (Traud, 2016). The types of courses in culinary arts programs include laboratory based classes, such as food production, international cuisines, baking and pastry, food and beverage management and dining room services (Eanes, 2018). These classes are categorically practical and necessitate that students work in teams, conduct hands on skill practice, and have close interaction with their chef faculty and peers (Hertzman, \& Mass, 2012). Likewise, industry employers expect that culinary arts students will enter the workplace with specific skills and abilities (Müller et al., 2009). In general, most of the popular culinary arts programs focus on the technical cooking techniques with some possible exposure to leadership skills (Müller et al., 2009). These programs often incorporate externships that place students into real-life industry environments, offering opportunities to gain practical expertise and create valuable contacts within the industry (Edens, 2011). Therefore, culinary arts students enter the workforce with a set of skills learned and developed from the formal culinary education they received in school. Other examples of initiatives and collaborations that include industry related internships, joint research projects, joint participation in international or local competitions, and so on, might assist in developing stronger and more industry desirable skills of students (Zopiatis et al., 2014).

\section{$1.1 \quad$ Literature Review}

There are several methods that contribute to deepening thinking skills of learners and offer opportunities for the development of intellectual abilities such as problem solving and creative thinking. Especially active methods are focused on nurturing the production of ideas for creative decision making and problem solving. Originally coined by Edward deBono (1967) who has been of the view that creative thinking should not be thought of as a special gift, but as achievable by all and improvable through training, lateral thinking, as a step-by-step method of creative thinking, involves "openended scanning techniques for generating options in the formative phases prior to decision selection, implementation and assessment" (deBono, 1971, 13). DeBono (1970) uses the term "lateral" to describe the characteristics of creative thinking and discusses lateral and vertical thinking as complementary components of the thinking process. Lateral skill permits the generation and consideration of alternative perspectives, while vertical analysis provides a method of refinement and systematic decision-making (pp. 39-45). The aim of lateral thinking is to generate new ideas and approaches, but its purpose is to facilitate the analytic system. In other words, according to deBono (1969, p.299; 1971, p.3, p.13), lateral thinking supports the decisional and problem solving processes with non-judgmental and non-rational sensing techniques for stimulating thinking in the pre-decisional phases. However, lateral thinking is not a model for decision or for action; it involves open-ended scanning techniques for generating options in the formative phases prior to decision selection, implementation and assessment (deBono, 1971, 13). Normally, following one's own experience or the experience of others to build on previous ways of problem solving is seen as a logical way of problem solving. On the other hand, some problems require an unfamiliar way of viewing and solving rather than following the same logical process. This unconventional thinking is described as deBono's (1971) lateral thinking and can be outlined in two phases to stimulate, discover, connect and focus the generation of new ideas by: (1) Demonstrating awareness of the problem or issue by identifying and understanding current patterns and ideas, (2) Changing ideas from outside by consciously ignoring the established patterns and deliberately introducing discontinuity by means of seemingly non-logical or irrational techniques: analogy, envelope or random word.

De Bono (1993) believes that lateral thinking enables an individual to look at problems from different angles rather than using only one method. To him, in order to gain mastery or perfection in the development of thinking skills, practice or training is necessary. He illustrates his point with the learning of how to ride a bike or to swim. At the beginning, while the learner feels confused due to the thought of learning them being difficult and unneeded, the existence of astonishment would be definitely unreasonable after acquiring a certain degree of skill for them. In a sense, lateral thinking indicates "experience, reasoning, analysis, and logic not as a starting point, but as a way of refining creative ideas" (DeBono, 1970, p. 61). Therefore, if someone could solve the problem with conventional approaches, there would not need lateral thinking. What to need is the talent to be imaginative and to apply creativity from one context to an entirely different one. From this point, DaVinci, who applied what he learned from human physiology and natural science to his studies, is a well-known example of a lateral thinker (Riding, 2006).

As shown in the chart in Figure 1, the basis of lateral thinking rests on efforts to be creative. Creativity cannot be reduced to only an intra-individual concept, it is also seen as the interaction between the person and the sociocultural surrounding (Ibrahim et al., 2020; Csikszentmihaly, 1996; Vaughan, Mallett, Davids, Potrac \& López-Felip, 2019). Trilling and Fadel (2009) suggest that today's world demands a fresh set of skills such as critical thinking, problem solving, effective communication, creativity, innovation, leadership, professionalism, teamwork and collaboration. Although conventional wisdom has been used extensively in the past to tackle business issues, nowadays, creativity has been becoming crucial in modern-day business as the increase in competition is forcing business to become more innovative (Okpara, 2007; Ware, 2020). Therefore, due to the evolving context within which businesses compete, there is a growing demand for greater integration of deliberate and intuitive thinking processes (Matzler, Uzelac, \& Bauer, 2014) and so, the ability to think laterally is becoming increasingly essential in individuals' working coherently with others as effective members of a productive team in workplaces of 21 st century. Lateral thinking, due to containing new ideas or different solutions within itself to help people come up with fresh ways of solving problems, insures that the 
team is not stuck in established patterns of thinking about problems. On the other hand, interacting individuals in teams and sharing their ideas will provide how well the team moves from cognitive category to cognitive category and help teams avoid getting mired in thinking ruts rather than following pre-existing cognitive paths (de Bono, 1991). Groupwork is a specific situation designed to encourage collaboration together over time to achieve some set purpose, goal or project in a small group context (Naquin \& Tynan, 2003).

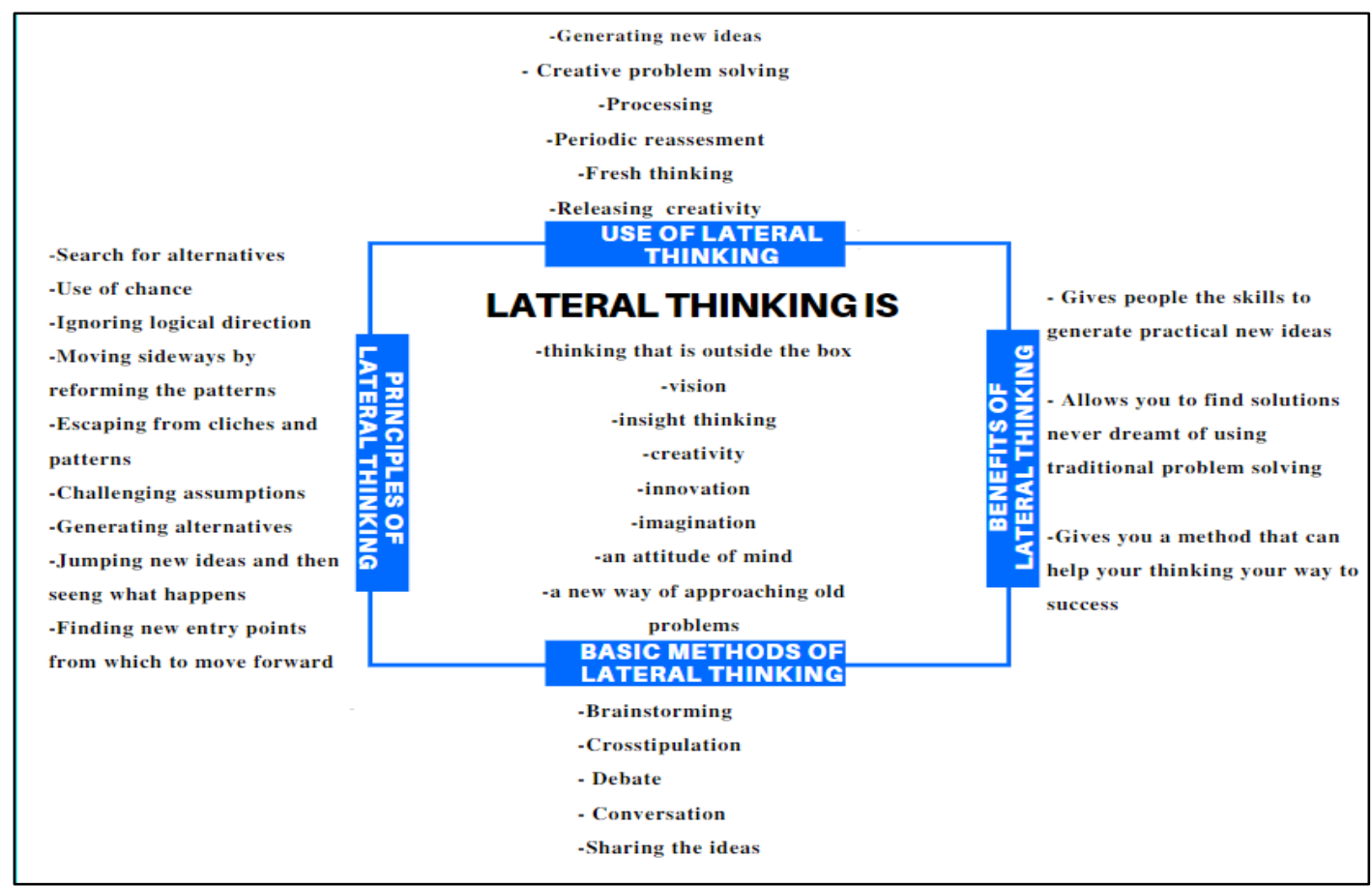

Fig. 1 - Lateral thinking

Team success that relies upon synergism existing between all group members is "not only a function of group members' talents and the existing resources but also the processes group members use to interact with each other to accomplish the work" (Marks, Mathieu, \& Zaccaro, 2001, p. 356). A team is not merely people belonging to the same group or co-acting in the same workplace. An essential characteristic of teams is that team members must organize their decisions and activities through sharing information and resources to achieve common goals by using their individual knowledge, experience and skills via dynamic interaction with other team members (Berber, Slavić \& Aleksić, 2020). Thus, defining groupwork requires an explication of what a group does when it acts as a team, and it is considered an effective way to create synergy (Mohamad et al., 2021; Driskell, Salas \& Driskell, 2018; Yang, 2016). Effective groupwork depends on each member being fully committed to the following principles suggested by Kagan (1994): (1) positive interdependence including that every member of the team works interdependently with the other members, so that every member achieves. (2) Individual responsibility, namely taking every team member's his/ her own responsibility in order to contribute to the work. (3) Equal participation which explains every team member's having the opportunity for maximum contribution to the collective work in line with their abilities. (4) Group processing which is related to reflecting team members' own progress. (5) Simultaneous interaction indicates all team members' simultaneously different contributions. In groupwork, lateral skill permits the generation and consideration of alternative perspectives and the traits of lateral thinking during group decision-making process include (a) an atmosphere of openness, (b) critical evaluation of assumptions and conclusions, (c) willingness to air uncertainties and objections, (d) objectivity and a tolerance for ambiguity, (e) exploration of many alternatives, (f) cross-checks and a display of the habit of approaching the problem from different viewpoints, $(\mathrm{g})$ the deliberate introduction of outside opinions, $(\mathrm{h}$ ) encouragement of opposing perspectives (i) demystification of boundaries, (j) construction of alternative scenarios and, (k) suspension of judgment (Burgh, 2016).

Collaborative learning is a learning process in which two or more people interact actively to learn something together (Darling-Hammond, Flook, Cook-Harvey, Barron, \& Osher, 2020) and requires working together toward a common goal (Noguera, Darling-Hammond, \& Friedlaender, 2017). Although the terms collaborative learning and cooperative learning are often used interchangeably, there are some key differences. Cooperative learning is non-competitive learning and requires students working together to succeed a common purpose (Johnson\& Johnson, 2009). While cooperation is normally achieved via labor division in which each person is responsible for some portion of work, collaboration includes all group members' working together on the same task, rather than separating portions of the task (Sawyer, \& Obeid, 2017). The expectation in collaboration depends on individual abilities to complete a given task more quickly more 
effectively and more satisfactorily (Barkley, Major, \& Cross, 2014). On the other hand, employees are often required to work in teams in order to successfully complete organizational tasks, for which formal education systems should prepare students. Therefore, collaborative learning not only facilitates lateral communication and team-based organizational designs but also encourages people to consider things from different perspectives in order to arrive at the solution from another angle (Davidson, Major,\& Michaelsen, 2014) as in lateral thinking.

\subsection{Aim of the Study}

This research aimed to compare and interpret the findings from the evaluation of the effect of lateral thinking dispositions (LATD) on groupwork in a collaborative learning environment through the Rasch, SPSS and Maxqda programs. In the frame of literature search process, it is apparent that although a variety of studies have indicated collaborative learning's positive effect on creative thinking (Gibson, Irving \& Seifert, 2018; John \& Meera, 2014; Kaplan Parsa, 2016; Karakaya, 2011; Korte, 2014; Leeuwen \& Janssen, 2019; Pun, 2012) and critical thinking ( Kazanc1, 2014; Nezami, Asgari \& Dinarvand, 2013; Özdemir, 2005; Uysal, 2009; Zhang, 2009), no studies involving the effect of lateral thinking dispositions on a collaborative learning environment have been undertaken so far. Therefore, this study aims to contribute to the literature and the related field by interpreting, comparing and evaluating the findings in order to present important insights to future researchers. Additionally, this research is also expected to make an impact in the scientific field both nationally and internationally due to its enriched methodology in which the data were analysed multidimensionally within the frame of methodological pluralism to present a broader and more significant results in both general and specific senses.

Methodological pluralism rests on the basis of selecting the most appropriate methods for the essence of the problem which is being researched (Payne, 2006). The wealth of data resources enables research to be evaluated from different points of view and enhances the quality of research (Patton, 2002). Therefore, this research is intended to reach more comprehensive and reliable results by enriching the methodology with a combination of diverse methods and analysis programs in a single study. In this regard, while in the quantitative phase of the study descriptive analysis was used through the Rasch FACETS and SPSS programs, in the qualitative phase, which was carried out according to COREQ checklist, thematic analysis was conducted through the Maxqda 11 program. In order to fulfil the general purpose of the study, the following sub-aims have been established.

Within the frame of the Rasch measurement model:

a) A general analysis of views on LATD of the 12 students who performed groupwork in two groups each containing 6 students.

b) The analysis of the judges with regard to their severity or leniency.

c) An item difficulty analysis regarding the LATD scale used to evaluate LATD of students.

d) The analysis of any bias of judges.

e) Within the frame of descriptive analysis:

f) The evaluation of students' views on LATD in terms of gender and high school graduation variables.

g) Within the frame of thematic analysis:

h) Examining the positive effects and challenges of LATD on groupwork in terms of academic, social and psychological perspectives.

\section{Method}

This is a mixed methods study within the frame of methodological pluralism and consists of both quantitative and qualitative phases. In mixed model designs, a combination of quantitative and qualitative methods can strengthen the depth and breadth of understanding (Creswell \& Plano Clark, 2011) and is expected to contribute to obtaining valid and reliable findings (Creswell, 2003).

In the quantitative phase of the research, descriptive analysis was performed through the Rasch Measurement Model and SPSS program. The Rasch Measurement Model is a unidimensional measurement model that calculates the relationship between item difficulty and personal ability in logit scale units (Embretson \& Reise, 2009). Rasch analysis provide probabilistic estimation of what a person can be expected to accomplish given the person ability and item calibration (Smith, 2000). Multi-faceted Rasch measurement model offers a way to adjust decisions about the level of descriptors or samples of performance, to take account of the severity/leniency of judges, and items difficulty (North, 1993). The Rasch model was utilized to obtain outcomes regarding the evaluation of LATD of the students and to identify the participant bias. The SPSS program was performed to obtain results on the participation levels of the respondents regarding the evaluation of their LATD and whether their LATD change according to the variables of the study.

In the qualitative phase of the research, the case study approach was conducted in order to reveal in-depth, multifaceted explorations of complex issues in their real-life settings (Creswell, 2003) under the guidelines of Consolidated Criteria for Reporting Qualitative Research (COREQ) statement developed by Tong, Sainsbury, and Craig (2007) that provides guidance to researchers drawing on qualitative methods. Through thematic analysis, it was aimed to reveal the positive effects and challenges of LATD on groupwork in terms of academic, social and psychological perspectives. 


\subsection{Participants}

Methodological pluralism, which is usually done in case studies, refers to the use of a series of methods by researchers within the scope of the same research. This allows to maximize validity and reliability by triangulating quantitative and qualitative data (May, Hunter, \& Jason, 2017). For the triangulation of the data, the study was conducted in three samples within the scope of methodological pluralism (for SPSS analysis: $N=83$; for thematic analysis: $N=66$; and, for the Rasch analysis 16+3), namely, as a total number, 86 participants' ( 83 students and 3 faculty members) views were included in the analyses. The research contained the opinions of 83 of the 91 freshmen students studying Gastronomy and Culinary Arts in the Faculty of Tourism at a state university during the fall term of the 2018 and 2019 academic year in Turkey (See Table1), who were applied to collaborative learning in Introduction to Gastronomy and Culinary Arts class. While all the students in the study universe $(n=83 ; 39$ female and 44 male) were included in the SPSS analysis, for the qualitative analysis, the sample of the study comprised 66 (29 female and 37 male) freshmen students who were selected on a voluntary basis depending on voluntary response sampling in which instead of the researcher choosing participants and directly contacting them, people volunteer themselves (Muriawa, 2015). For the Rasch analysis, besides 16 freshmen students accepting to participate this aspect of the study voluntarily in order to evaluate their 12 friends, 3 faculty members who have the responsibilities of the groupwork of the 12 students were also included. The aim of choosing these 12 students in two groups is that since the groups were heterogeneous, although there were students who graduated from tourism or cooking related vocational high schools and had work experience, certificate and prizes on their area, there were also those who graduated from regular high schools or Anatolian high schools and had no work experiences or prizes. Thus, the students having work experience in each group were supposed to combine their practical and technical skills with self-confidence and exhibit high level of LATD in groupwork as well, and that's why, the LATD of these 12 students were found remarkable to evaluate within the scope of this study and they were coded as:

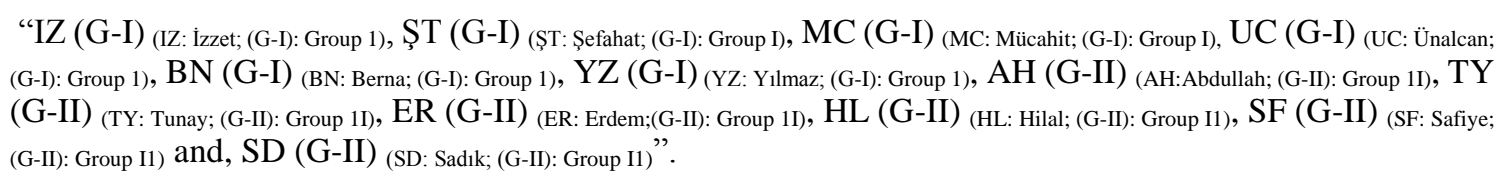

Demographic characteristics of the participants are given in Table 1.

Table 1 - Distribution of the participants taking part in the sample according to variables

\begin{tabular}{llcc}
\hline $\begin{array}{l}\text { Variables } \\
\text { Gender }\end{array}$ & Female & $\mathbf{N}$ & $\mathbf{\%}$ \\
& Male & 44 & 53.0 \\
& & 39 & 47.0 \\
\hline & Tourism Vocational High School & & \\
High School & Anatolian Hotel and Tourism High School & 8 & 9.6 \\
Graduation & Anatolian Technical-Vocational High School & 11 & 13.3 \\
& Anatolian High School & 25 & 30.1 \\
& Regular High School & 23 & 27.7 \\
Total & & 16 & 19.3 \\
\hline
\end{tabular}

\subsection{Data Collection Tools}

In the quantitative part of the study, Lateral Thinking Disposition (LATD) Scale developed by Semerci (2016) was used as a data collection tool for both the Rasch analysis and SPSS analysis. This 5- point Likert scale with nine items is a unidimensional scale which explains $46.637 \%$ of the total variance (Semerci, 2016). The Cronbach Alpha Coefficient of LATD scale was found to be 0.794; the value of Bartlett test was $1585.363(D F=36, p=0.000)$. Confirmatory factor analysis was conducted through AMOS program (Chi-square $=6,744, S D=16, G F I=0.998, C F I=1.000, R M S E A=$ 0.000) (Semerci, 2016).

The qualitative data was collected through a semi structured interview form developed by the researcher in the light of the literature review and expert opinions. The form consisted of open-ended questions, and students were asked to express their views on the effect of LATD on groupwork in terms of academic, social and psychological perspectives.

\subsection{Data Analysis}

The analyses of the data obtained from each phase of the study within the frame of methodological pluralism were performed separately and sequentially. Simultaneous and sequential operations are conducted for studies containing more than one analysis type to determine a common unity (Creswell, Plano Clark, Gutmann, \& Hanson, 2003). In the analysis of quantitative data both the Linacre version of the Rasch model (1993) in the FACETS analysis program and the SPSS 
18.0 program were utilized. In the Rasch measurement model, the three facets of this study were: (1) judges (16 students and 3 faculty members); (2) the scale items (9 items) concerning the LATD; (3) 12 students evaluated in terms of groupwork. Additionally, arithmetic means, standard deviations of the quantitative data were calculated through the SPSS program. On the other hand, thematic analysis, a method for identifying, analysing, and reporting themes (Braun \& Clarke, 2006), for the qualitative data was used in line with the aim of identifying categories of statements reflecting students' views on the effects of LATD on groupwork and for generating initial codes and combining codes into overarching themes. Analysis began with the detailed reading the transcribed participant views from beginning to end two times by the researcher and a coder in order to form themes and codes. Two models with the titles of advantages of LATD on groupwork and challenges of LATD on groupwork were identified.

The themes for the both models as academic, social and psychological perspectives were uploaded to the Maxqda program along with their relevant codes. On the other hand, interrater reliability, tested by Cohen's kappa statistical measure (Cohen, 1960) to ensure the agreement between the research data coders was calculated separately for each theme and given in Appendix 1. Kappa value between 0.0 to 0.20 means slight agreement; 0.21 to 0.40 moderate agreement; 0.41 to 0.60 fair agreement; 0.61 to 0.80 substantial agreement; 0.81 to 1.00 almost perfect agreement (Cohen, 1960). In the present study, related to the first category, the advantages of LATD on groupwork, the Kappa values for the themes were aligned as 0.81 for academic perspective; 0.83 for social perspective and; 0.83 for psychological perspective. As for the second category, the challenges of LATD on groupwork, the Kappa values were 0.89 for academic perspective; 0.85 for social perspective and; 0.86 for psychological perspective (See Appendix 1). It is apparent that all the Kappa values obtained from the themes of this study were between substantial agreement and almost perfect agreement. Additionally, each participant of the qualitative part of the study were coded as P1-M/F (P: Participant; 1:Participant No; M:Male/F:Female) and these codes were used during the analysis and interpretation phases.

\section{Findings}

\subsection{Quantitative Findings Regarding the Rasch Measurement Model and SPSS}

The analysis of the views of the participants on the LATD of their 12 friends who were divided into two groups of 6 for a group and they performed groupwork in the class of Introduction to Gastronomy and Culinary Arts was carried out via the multi-faceted Rasch model. General information related to the three facets of this study was given in the calibration map in Table 2.

Table 2 - Data calibration map

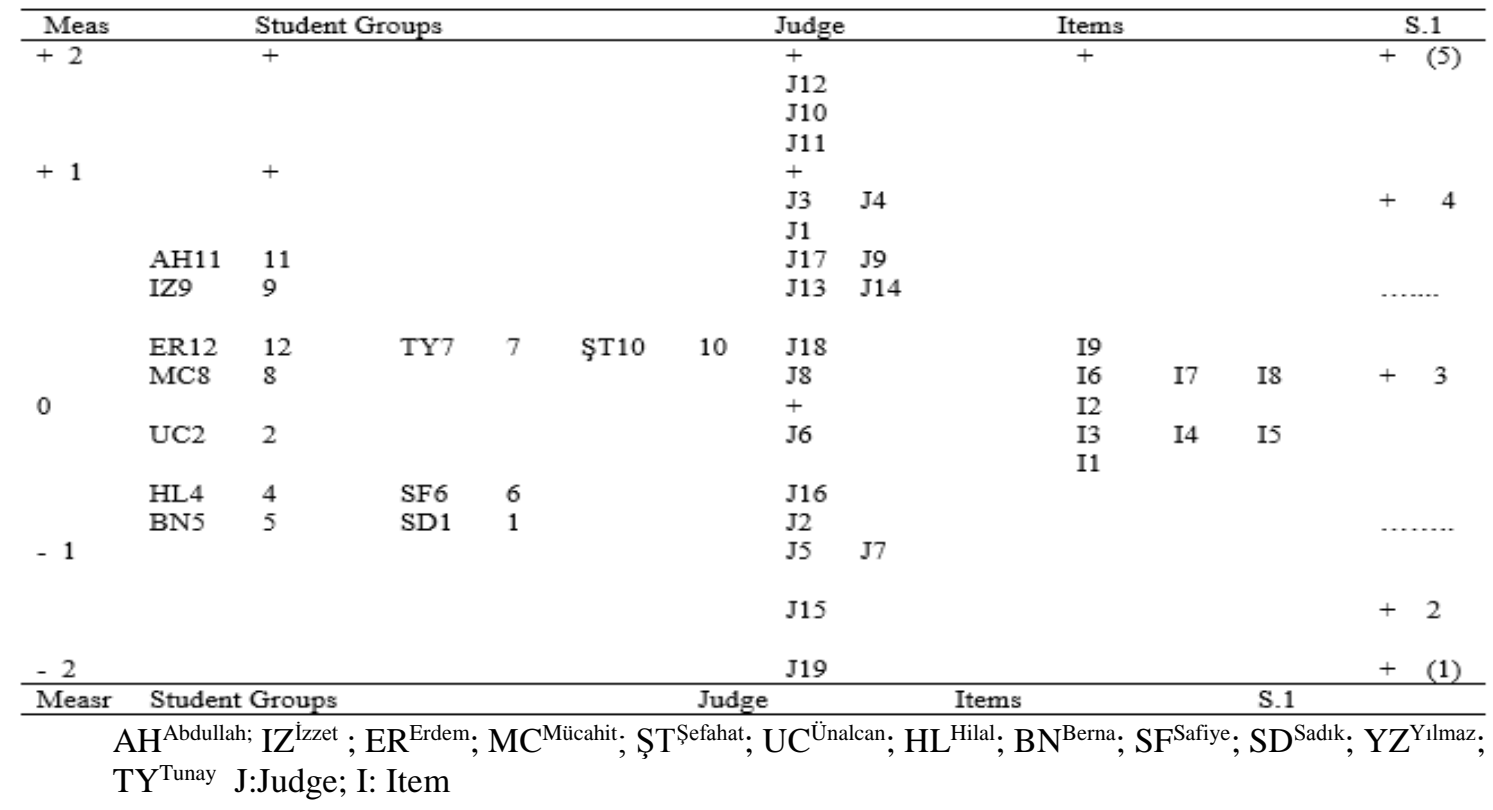

In Table 2, the students evaluated, judges, and items were indicated with different columns separately in the calibration map. The logit measurement located between (-) and (+) on the left side of the map is the same for the three facets. The three facets of the study, namely, the LATD of the students evaluated, severe or lenient scores of judges and the difficulty levels of the items were listed in the logit scale on the map. In the column belonging to the students evaluated, while the students coded as AH has the highest level of LATD, the students coded as BN, SD, and YZ have the lowest level. In the column including the scores of judges, while the judge having the most lenient behaviour was J12, the judge having the most severe behaviour was J19. According to the "Lateral Thinking Dispositions" column, 
while the item coded as I-9 I can be interested in improbable approaches while thinking is the most difficult item to answer, the item coded as I-1 I'm clever at innovation is the easiest item to answer.

This study also attempted to obtain more detailed information through the use of SPSS analysis regarding whether the level of LATD of students differs in terms of high school graduation and gender variables. Additionally, arithmetic mean of all the items were calculated through the SPSS program, as well. While the I-1 coded item had the lowest arithmetic mean (mean $=3.26 ; S D=1.38$ ) in the SPSS analysis, the I-9-coded item, on the other hand had one of the highest levels (mean $=3.84 ; S D=.818$ ) (See Appendix 2). This result shows consistency with the findings of the Rasch measurement.

\subsubsection{Analysis of the LATD of the Students Evaluated Within the Frame of the Rasch Analysis}

Table 3 gives a detailed measurement report regarding the analysis of the LATD of the students evaluated within the frame of the Rasch analysis. The scores were aligned from the highest score to the lowest one. In this regard, the highest score belonged to the AH coded student from the second group and the lowest scored student was SD coded one from the first group.

Table 3 - Students' measurement report

\begin{tabular}{|c|c|c|c|c|c|c|c|c|c|c|c|}
\hline \multirow{2}{*}{$\begin{array}{l}\text { Obsvd } \\
\text { Score } \\
632\end{array}$} & \multirow{2}{*}{$\begin{array}{l}\text { Obsvd } \\
\text { Count } \\
171\end{array}$} & \multirow{2}{*}{\begin{tabular}{l}
\multicolumn{1}{c}{ Obsvd } \\
Average \\
3.7
\end{tabular}} & \multirow{2}{*}{$\begin{array}{c}\begin{array}{c}\text { Fair } \\
\text { Average }\end{array} \\
3.78\end{array}$} & \multirow{2}{*}{$\begin{array}{c}\text { Measr } \\
.59\end{array}$} & \multirow{2}{*}{$\begin{array}{c}\text { Model } \\
\text { S.E. } \\
.09\end{array}$} & \multicolumn{2}{|c|}{$\begin{array}{c}\text { Infit } \\
\text { Mnsq zstd }\end{array}$} & \multicolumn{2}{|c|}{$\begin{array}{c}\text { Outfit } \\
\text { Mnsg zstd }\end{array}$} & \multirow{2}{*}{$\begin{array}{c}\mathrm{nu} \\
11\end{array}$} & \multirow{2}{*}{$\begin{array}{c}\begin{array}{c}\text { Student } \\
\text { group }\end{array} \\
\text { AH11 }\end{array}$} \\
\hline & & & & & & 1.1 & 0 & 1.0 & 0 & & \\
\hline 619 & 171 & 3.6 & 3.70 & .49 & .09 & 1.2 & 1 & 1.2 & 1 & 9 & IZ9 \\
\hline 587 & 171 & 3.4 & 3.48 & .25 & .09 & 1.0 & 0 & 1.0 & 0 & 7 & TY7 \\
\hline 583 & 171 & 3.4 & 3.46 & .22 & .09 & 1.1 & 0 & 1.1 & 0 & 10 & ŞT10 \\
\hline 574 & 171 & 3.4 & 3.40 & .15 & .08 & 1.2 & 1 & 1.1 & 1 & 12 & ER12 \\
\hline 570 & 171 & 3.3 & 3.37 & .13 & .08 & 0.9 & 0 & 0.9 & 0 & 8 & MC8 \\
\hline 544 & 171 & 3.2 & 3.19 & -.06 & .08 & 1.0 & 0 & 1.0 & 0 & 2 & $\mathrm{UC} 2$ \\
\hline 513 & 171 & 3.0 & 2.99 & -.28 & .08 & 0.9 & 0 & 0.9 & -1 & 4 & HL 4 \\
\hline 507 & 171 & 3.0 & 2.95 & -.32 & .08 & 1.0 & 0 & 0.9 & 0 & 6 & SF6 \\
\hline 499 & 171 & 2.9 & 2.89 & -.37 & .08 & 0.8 & -2 & 0.8 & -2 & 5 & BN5 \\
\hline 496 & 171 & 2.9 & 2.87 & -.39 & .08 & 0.9 & -1 & 0.9 & -1 & 3 & YZ3 \\
\hline 495 & 171 & 2.9 & 2.86 & -.40 & .08 & 1.0 & 0 & 1.0 & 0 & 1 & SD1 \\
\hline 551.6 & 171.0 & 3.2 & 3.24 & .00 & .08 & 1.0 & -0.1 & 1.0 & -0.2 & \multicolumn{2}{|c|}{ Mean (Count: } \\
\hline 47.2 & 0.0 & 0.3 & 0.32 & .34 & .00 & 0.1 & 1.1 & 0.1 & 1.1 & S.D & \\
\hline \multicolumn{2}{|c|}{ RMSE (Model) } & .08 & $\begin{array}{l}\text { Adj } \\
\text { S.D. }\end{array}$ & .33 & \multicolumn{2}{|c|}{ separation } & 3.85 & \multicolumn{2}{|c|}{ reliability } & .94 & \\
\hline \multicolumn{2}{|c|}{$\begin{array}{l}\text { Fixed (all } \\
\text { same) }\end{array}$} & \multicolumn{2}{|c|}{ Chi-square: 186.2} & d.f: 11 & \multicolumn{2}{|c|}{ Significance } & .00 & & & & \\
\hline \multicolumn{2}{|c|}{$\begin{array}{l}\text { Random } \\
\text { (normal) }\end{array}$} & \multicolumn{2}{|c|}{ Chi-square: 11.0} & d.f: 10 & \multicolumn{2}{|c|}{ Significance } & .36 & & & & \\
\hline
\end{tabular}

In Table 3, the reliability co-efficient in the Rasch analysis was calculated to be .94 and the separation index was 3.85. These high values indicated that the LATD rankings of the students can be distinguished from each other by high reliability. The standard error (RMSE-Root Mean Square Standard Error) value related to the LATD of the students was computed to be .08 which indicates a low level of standard error. Since this value tells us how much smaller the RMSE error will be than the standard error. The adjusted standard deviation value $(=.33)$ was below the critical value of 1.0 . On the other hand, infit and outfit values were between the ranges of $0.6-1.4$, namely, in the acceptable quality control limit (Wright \& Linacre, 1994). From the results given in Table 2, it is also clear that there were statistically significant differences among the LATD of the students evaluated $(\chi 2=186.2, \mathrm{SD}=11, \mathrm{p}=.00)$. The ranking of the students from the highest LATD scores to the lowest ones are follows: "AH (G-II), IZ (G-I), TY (G-II), ŞT (G-I), ER (G-II), MC (GI), UC (G-I), HL (G-II), SF (G-II), BN (G-I), YZ (G-I), SD (G-II)”.

On the other hand, the findings obtained from the Rasch analysis were compared with the SPSS results gathered from the views of the participants in terms of high school graduation variable and descriptive statistics were given in Appendix 3. The results indicated that the general arithmetic means of the students who graduated from Tourism Vocational High School ( $\overline{\mathrm{x}}=4.03 \pm .70)$, from Anatolian Hotel and Tourism High School $(\overline{\mathrm{x}}=3.83 \pm .71)$, from Anatolian Technical-Vocational High School ( $\overline{\mathrm{x}}=4.00 \pm .81)$, from Anatolian High School ( $\overline{\mathrm{x}}=3.73 \pm .65)$ and, from Regular High School $(\overline{\mathrm{x}}=3.68 \pm .92)$ were found at the level of "Mostly Agree". However, no statistically significant differences among schools were found $(\mathrm{F}(4-78)=1.039, \mathrm{P}>0.05)$. It is apparent from the results regarding the high school graduation variable that the students graduated from regular high school had the lowest score while those who graduated from vocational high schools had the highest score in terms of reflecting their LATD on groupwork. In this vein, the SPSS results have shown consistency with the Rash analysis results. Since, in the Rash analysis, the students coded IZ, TY, ŞT, MC, who graduated from tourism related high schools had received higher scores from the juries because they had reflected their LATD on groupwork. 


\subsubsection{Analysis of Judges}

The leniency or severity of judges on the evaluation of the students' LATD in groupwork was given in Table 3 . It was apparent from the results that the judge coded J12 was the "most lenient" with 472 points and the judge coded J19 was the "severest" with 189 points.

As it was indicated in Table 4, there was a statistically significant difference between the severity/ leniency of the judges $(x 2=1095.6, S D=18, p=.00)$. On the other hand, the separation index of the judges was 7.95 and the reliability coefficient was 0.98 . The separation and reliability indices calculated for the rater facet indicate the reliably difference between the judges rather than the reliably similarity (Haiyang, 2010). Thus, these values' being high shows the differences in the judges' severity/ leniency. The Rasch model has two indicators as the infit and outfit mean square indices. While infit is "sensitive to unexpected responses to items near the person's ability level", outfit is related to "difference between observed and expected responses regardless of how far away the item endorsability is from the person's ability" (McCreary, Conrad, Conrad, Funk,\& Dennis, 2013, p. 7). The results of the infit and outfit statistical values of the facets revealed that while fifteen of the 19 judges were within the range of $0.6-1.4$, the accepted quality control values, the judges J3, J6, J7 and J9 were out of the expected values of the infit and outfit square averages. However, the judges J3, J6, J7 and J9 whose findings related to the infit and outfit mean square values exceeded the expected limit have not displayed consistent behaviours in scoring.

Table 4 - Judges' severity/leniency report

\begin{tabular}{|c|c|c|c|c|c|c|c|c|c|c|c|}
\hline \multirow{2}{*}{$\begin{array}{l}\begin{array}{l}\text { Obsvd } \\
\text { Score }\end{array} \\
472\end{array}$} & \multirow{2}{*}{$\begin{array}{l}\text { Obsvd } \\
\text { Count } \\
108\end{array}$} & \multirow{2}{*}{$\begin{array}{l}\begin{array}{c}\text { Obsvd } \\
\text { Average }\end{array} \\
4.4\end{array}$} & \multirow{2}{*}{$\begin{array}{c}\begin{array}{c}\text { Fair } \\
\text { Average }\end{array} \\
4.39\end{array}$} & \multirow{2}{*}{$\begin{array}{l}\text { Measr } \\
1.74\end{array}$} & \multirow{2}{*}{$\begin{array}{c}\text { Mode1 } \\
\text { S.E. }\end{array}$} & \multicolumn{2}{|c|}{$\begin{array}{c}\text { Infit } \\
\text { Mnsq zstd }\end{array}$} & \multicolumn{2}{|c|}{$\begin{array}{l}\text { Outfit } \\
\text { Mnsq zstd }\end{array}$} & \multirow{2}{*}{$\begin{array}{c}\mathrm{nu} \\
12\end{array}$} & \multirow{2}{*}{$\begin{array}{l}\text { Judge } \\
\text { J12 }\end{array}$} \\
\hline & & & & & & 0.8 & -1 & 0.9 & 0 & & \\
\hline 456 & 108 & 4.2 & 4.24 & 1.48 & .12 & 0.6 & -3 & 0.6 & -3 & 10 & J10 \\
\hline 430 & 108 & 4.0 & 4.00 & 1.13 & .11 & 0.7 & -2 & 0.7 & -2 & 11 & J11 \\
\hline 412 & 108 & 3.8 & 3.83 & .91 & .11 & 1.5 & 3 & 1.5 & 3 & 3 & J3 \\
\hline 408 & 108 & 3.8 & 3.79 & .87 & .11 & 0.9 & -1 & 0.9 & 0 & 4 & J4 \\
\hline 402 & 108 & 3.7 & 3.74 & .80 & .10 & 0.5 & -4 & 0.6 & -4 & 1 & $\mathrm{~J} 1$ \\
\hline 396 & 108 & 3.7 & 3.68 & .73 & .10 & 1.4 & 2 & 1.4 & 2 & 17 & J17 \\
\hline 392 & 108 & 3.6 & 3.64 & .69 & .10 & 0.3 & -7 & 0.3 & -7 & 9 & J9 \\
\hline 387 & 108 & 3.6 & 3.60 & .64 & .10 & 0.6 & -4 & 0.6 & -3 & 14 & 14 \\
\hline 381 & 108 & 3.5 & 3.54 & .57 & .10 & 1.2 & 1 & 1.2 & 1 & 13 & $\mathrm{~J} 13$ \\
\hline 361 & 108 & 3.3 & 3.35 & .37 & .10 & 1.4 & 2 & 1.4 & 2 & 18 & J18 \\
\hline 355 & 108 & 3.3 & 3.29 & .31 & .10 & 1.4 & 2 & 1.3 & 2 & 8 & J8 \\
\hline 299 & 108 & 2.8 & 2.76 & -.24 & .10 & 1.7 & 4 & 1.7 & 4 & 6 & J6 \\
\hline 281 & 108 & 2.6 & 2.59 & -.42 & .10 & 0.4 & -5 & 0.4 & -5 & 16 & J16 \\
\hline 260 & 108 & 2.4 & 2.39 & -.64 & .10 & 0.7 & -2 & 0.7 & -2 & 2 & $\mathrm{~J} 2$ \\
\hline 255 & 108 & 2.4 & 2.35 & -.70 & .10 & 2.0 & 6 & 2.0 & 6 & 7 & $\mathrm{~J} 7$ \\
\hline 251 & 108 & 2.3 & 2.31 & -.74 & .10 & 0.9 & -1 & 0.9 & -1 & 5 & J5 \\
\hline 232 & 108 & 2.1 & 2.13 & -.95 & .10 & 0.7 & -2 & 0.7 & -2 & 15 & $\mathrm{~J} 15$ \\
\hline 189 & 108 & 1.8 & 1.73 & -1.53 & .12 & 0.8 & -1 & 0.8 & -1 & 19 & J19 \\
\hline 348.4 & 108.0 & 3.2 & 3.23 & .26 & .11 & 1.0 & -0.7 & 1.0 & -0.6 & \multirow{2}{*}{\multicolumn{2}{|c|}{$\begin{array}{l}\text { Mean } \\
\text { (Count:19) } \\
\text { S.D. }\end{array}$}} \\
\hline 80.4 & 0.0 & 0.7 & 0.76 & .87 & .01 & 0.5 & 3.7 & 0.4 & 3.6 & & \\
\hline \multicolumn{2}{|c|}{ RMSE (Mode1) } & .11 & $\begin{array}{l}\text { Adj } \\
\text { S.D. }\end{array}$ & .86 & separati & & 7.97 & reli & & .98 & \\
\hline \multirow{2}{*}{\multicolumn{2}{|c|}{$\begin{array}{l}\text { Fixed (all } \\
\text { same) } \\
\text { Random } \\
\text { (normal) }\end{array}$}} & \multicolumn{2}{|c|}{ Chi-square: 1095.6} & d.f: 18 & \multicolumn{2}{|c|}{ Significance } & .00 & & & & \\
\hline & & \multicolumn{2}{|c|}{ Chi-square: 18.0} & d.f: 17 & \multicolumn{2}{|c|}{ Significance } & .39 & & & & \\
\hline
\end{tabular}

In the SPSS analysis aspect, it was also aimed to reveal whether the level of LATD of students differs in terms of gender variable and the corresponding data was presented in Appendix 4. With regard to the gender differences, both female $(N=39)$ and male $(N=44)$ participants exhibited high level of LATD. Although males obtained higher scores $(\bar{x}=3.95 ; S D=.89)$ than did their counterparts $(\bar{x}=3.71 ; S D=.72)$, there were no statistically significant differences $[p>.05]$ between the groups.

\subsubsection{Analysis of the Scale Items}

The clarity and appropriateness of the scale items used to evaluate the LATD of the students within the scope of this study was presented in Table 5 . 
Table 5 - Analysis of scale items

\begin{tabular}{|c|c|c|c|c|c|c|c|c|c|c|c|}
\hline \multirow{2}{*}{$\begin{array}{l}\text { Obsvd } \\
\text { Score }\end{array}$} & \multirow{2}{*}{$\begin{array}{l}\text { Obsvd } \\
\text { Count } \\
228\end{array}$} & \multirow{2}{*}{$\begin{array}{l}\text { Obsvd } \\
\text { Average } \\
3.1\end{array}$} & \multirow{2}{*}{$\begin{array}{c}\begin{array}{c}\text { Fair } \\
\text { Average }\end{array} \\
3.09\end{array}$} & \multirow{2}{*}{$\frac{\text { Measr }}{.16}$} & \multirow{2}{*}{$\begin{array}{c}\text { Model } \\
\text { S.E. } \\
.07\end{array}$} & \multicolumn{2}{|c|}{$\begin{array}{c}\text { Infit } \\
\text { Mnsq zstd }\end{array}$} & \multicolumn{2}{|c|}{$\begin{array}{l}\text { Outfit } \\
\text { Mnsq zstd }\end{array}$} & \multirow{2}{*}{$\begin{array}{l}\text { nu } \\
9\end{array}$} & \multirow{2}{*}{$\begin{array}{l}\text { Items } \\
\text { I9 }\end{array}$} \\
\hline & & & & & & 1.0 & 0 & 1.0 & 0 & & \\
\hline 720 & 228 & 3.2 & 3.17 & .08 & .07 & 1.1 & 0 & 1.0 & 0 & 7 & I7 \\
\hline 723 & 228 & 3.2 & 3.19 & .07 & .07 & 0.9 & -1 & 0.9 & -1 & 6 & I6 \\
\hline 724 & 228 & 3.2 & 3.19 & .06 & .07 & 1.1 & 0 & 1.1 & 0 & 8 & I8 \\
\hline 736 & 228 & 3.2 & 3.25 & .00 & .07 & 0.8 & -2 & 0.8 & -2 & 2 & I2 \\
\hline 745 & 228 & 3.3 & 3.30 & -.05 & .07 & 1.1 & 0 & 1.0 & 0 & 4 & I4 \\
\hline 749 & 228 & 3.3 & 3.32 & -.07 & .07 & 0.8 & -2 & 0.8 & -2 & 3 & I3 \\
\hline 750 & 228 & 3.3 & 3.33 & -.08 & .07 & 1.1 & 0 & 1.0 & 1 & 5 & I5 \\
\hline 767 & 228 & 3.4 & 3.41 & .17 & .07 & 1.2 & 1 & 1.0 & 1 & 1 & I1 \\
\hline 735.4 & 228.0 & 3.2 & 3.25 & .00 & .07 & 1.0 & -0.1 & 1.0 & -0.3 & & $t: 9)$ \\
\hline 18.1 & 0.0 & 0.1 & 0.09 & .10 & .00 & 0.1 & 1.4 & 0.1 & 1.3 & S.I & \\
\hline \multicolumn{2}{|c|}{ RMSE (Mode1) } & .07 & $\begin{array}{l}\text { Adj } \\
\text { S.D. }\end{array}$ & .06 & \multicolumn{2}{|c|}{ separation } & .87 & \multicolumn{2}{|c|}{ reliability } & \multicolumn{2}{|c|}{.43} \\
\hline \multirow{2}{*}{\multicolumn{2}{|c|}{$\begin{array}{l}\text { Fixed (all } \\
\text { same) } \\
\text { Random } \\
\text { (normal) }\end{array}$}} & \multicolumn{2}{|c|}{ Chi-square: 15.7} & d.f.: 8 & \multicolumn{2}{|c|}{ Significance } & .05 & & & & \\
\hline & & \multicolumn{2}{|c|}{ Chi-square: 8.0} & d.f.: 7 & \multicolumn{2}{|c|}{ Significance } & .33 & & & & \\
\hline
\end{tabular}

Related to item difficulty analysis, separation index was found to be .87 . It was clear that that there were significant distinctions between difficulties of items on the scale $(x 2=15.7, S D=8, p=.05)$. On the other hand, the standard error (RMSE) of the scale items was calculated to be .07 which is lower than the critical value 1.0. The adjusted standard deviation (Adj $S D=.06$ ) was also lower than the critical value of 1.0. When the infit and outfit mean squares of the items were examined, it was apparent that all data were within the acceptable value limits $(0.6-1.4$ range $)$ indicating the consistency of the items.

\subsubsection{Interaction Analysis of Judges' Bias}

The interaction analysis regarding the views of the judges on the LATD of the students was presented in Table 6. The bias analysis results revealed that some of the jury members exhibited extremely severe or lenient behaviours in scoring the LATD of the students.

Table 6 - Interaction analysis of LATD with judges 


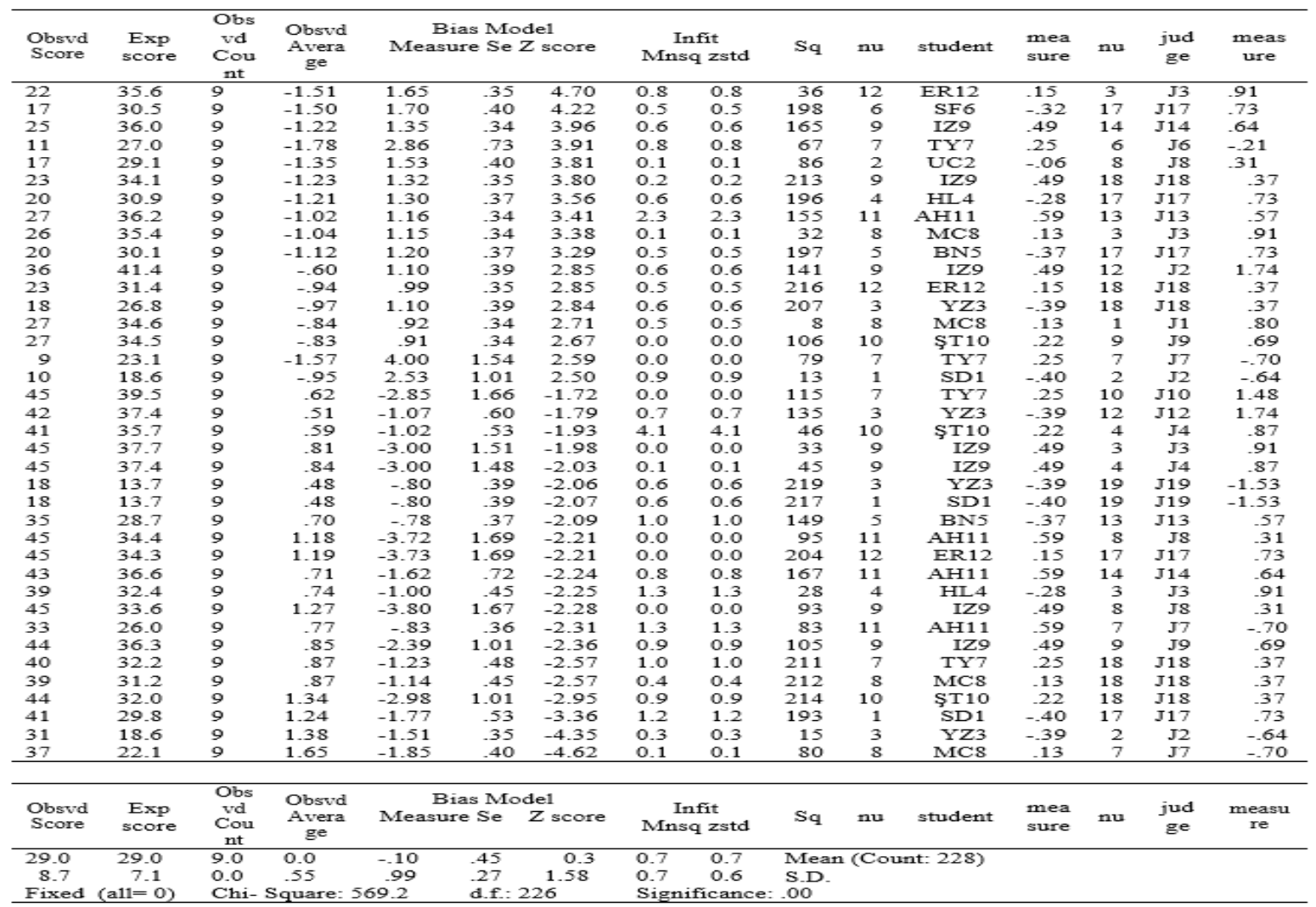

According to the interaction analysis results presented in Table 6 , the $\mathrm{J} 3$ has given 22 points $(Z=4.70)$ to the ER coded student instead of 35.6 points and 26 points $(Z=3.38)$ for the MC coded student instead of 35.4 points which indicates that this judge exhibited in a severe manner to these students. Whereas the same judge behaved leniently by giving 45 points $(Z=-1.98)$ instead of 37.7 to the IZ coded student and 39 points $(Z=-2.25)$ instead of 32.4 to the HL coded student. Similarly, while the $\mathrm{J} 17$ gave 17 points $(Z=4.22)$ instead of 30.5 for the SF coded student and 20 points $(Z=3.56)$ instead of 30.9 for the HL coded students, the same judge gave 45 points $(Z=-2.21)$ instead of 34.3 points for the ER coded student and 41 points $(Z=-3.36)$ instead of 29.8 for the SD coded student. This judge acted with severe or lenient behaviours when scoring the students in both groups.

\subsection{Findings Related to Qualitative Data}

In the qualitative aspect of the study, it was attempted to reveal the positive effects and challenges of LATD on groupwork in terms of academic, social and psychological perspectives through the use of the Maxqda 11 program. The findings were collected under two categories: (1) Positive effects of LATD on groupwork and (2) challenges of LATD on groupwork. Both the two categories included the themes of academic, social and psychological perspectives. In this regard, the participants' views regarding the effect of LATD on groupwork were examined in detail and then the codes under each theme were analysed, modelled and presented in Figure 2 Figure 3 and Figure 4.

\subsubsection{Findings Related to Positive Effects of LATD on Groupwork}




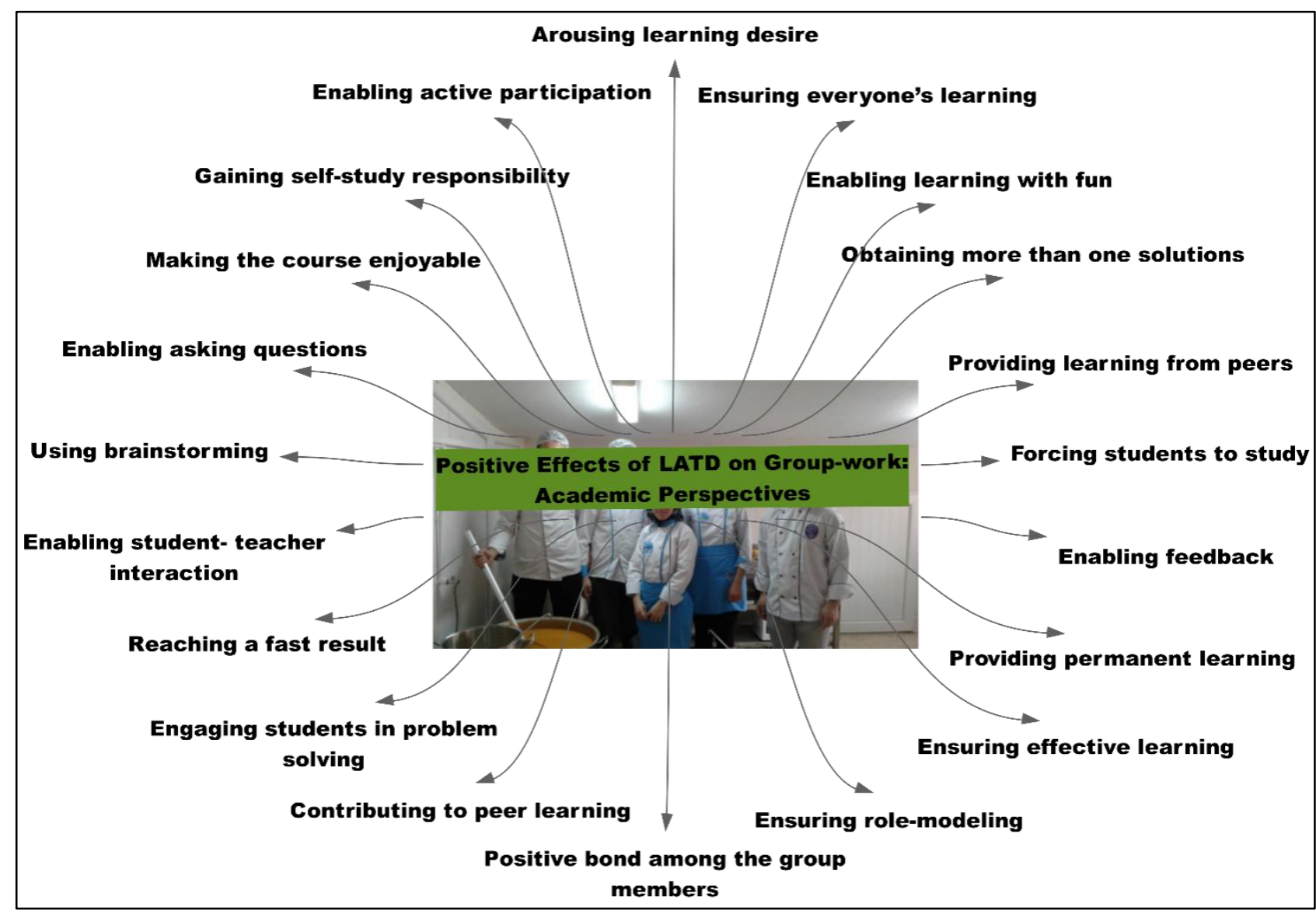

Fig. 2 - Positive effects of LATD on groupwork in terms of academic perspectives

Some certain codes associated with the theme "academic perspectives" given in Figure 2 included "Gaining selfstudy-responsibility", "Providing learning from peers in a group", "Enabling the sharing of diverse perspectives", "Being open to innovations", "Enabling asking questions and inquiry learning", and "Brainstorming for group interaction". Related to these codes, the participant coded P31/M stated, I try to learn by discussing and questioning each group member's points of view and listening to their experience since having insight into the group members' cultural backgrounds and their work experiences helps me reach better solutions and performance by interpreting subject matter from diverse perspectives and brainstorming. Another participant coded P8/F stressed the importance of peer learning and said I think it is safer to ask a peer for help in learning than to the teacher since my peers speak my language and have a clearer way to explain something that I am in difficulty to understand than a teacher has. Another participant coded P17/M uttered her feelings about peer learning as Working with peers helps me out a lot so as to understand the bigger picture by combining all of my fragmented ideas as a whole. However, the participant P19/F touched on the ignorance of creativity in groupwork and added, There's no point in being a creative person unless you have peers around your group willing to broaden their horizons and being open to innovations. According to the views of the participant coded P28/M, individual responsibilities contribute to the emergence of quality work and he added, I need to fulfil my individual responsibilities such as gaining self-study habits, delivering my own work on time, individual contributions to the group interaction and supporting each group member's work in order for my group to function fruitfully. 


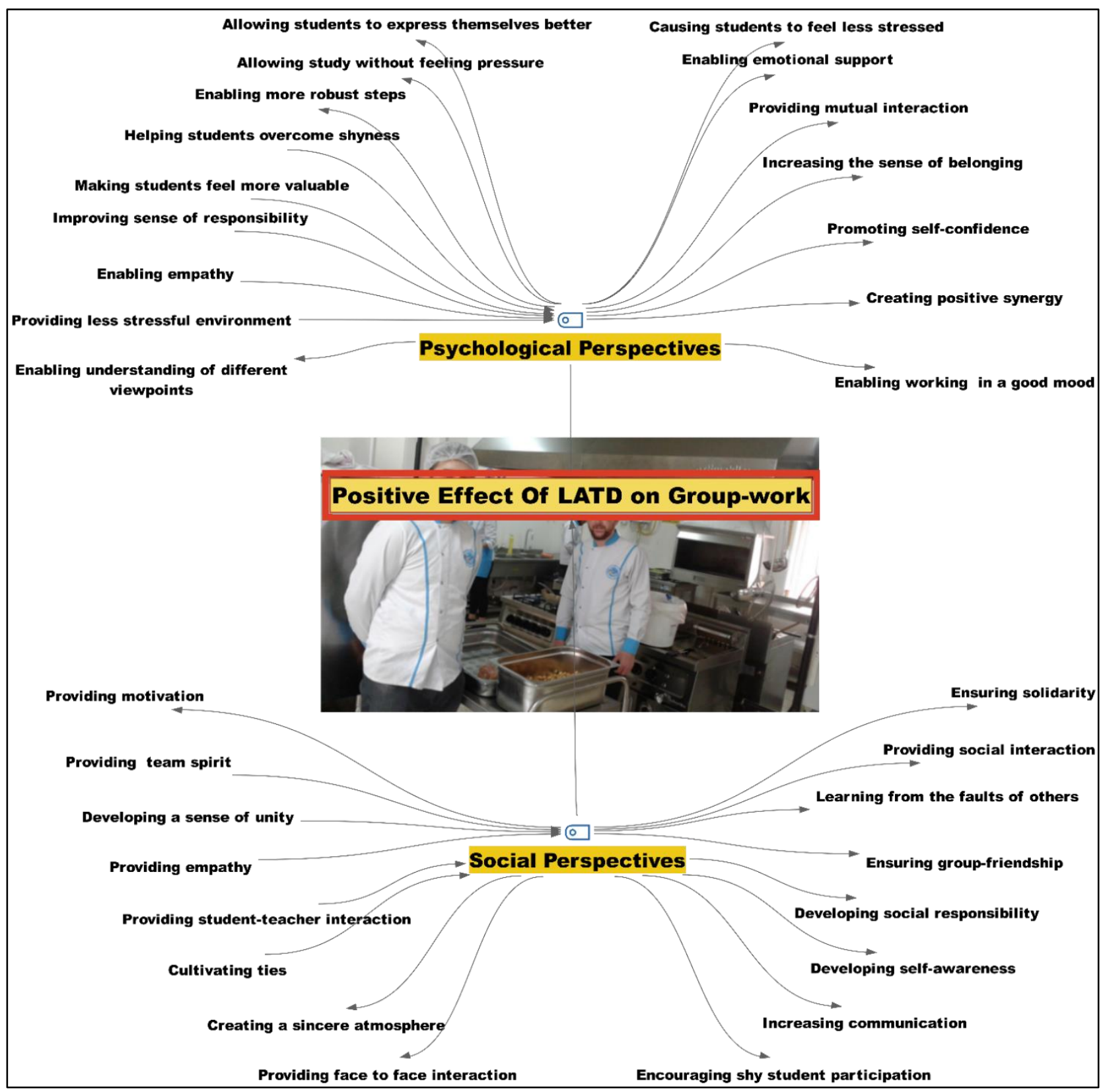

Fig. 3 - Positive effects of LATD on groupwork in terms of social and psychological perspectives

In relation to the theme "social perspectives", given in Figure 3, some remarkable codes are as follows: "Increasing communication and socialization", "Providing empathy", "Contributing to team spirit development", "Providing regular school attendance in order not to leave group members in the lurch". Most participants stressed the importance of strengthen the communication bond among the group members. For example, according to the participant coded P5/M opinions, Groupwork provides interaction and good communication between us, therefore, when there is interaction, we can learn more. However, there were different perspectives on socialization. While the participant coded P56/M expressed his idea on socialization, he pointed out that social interactions for every member of the group was not important and he continued... I have a friend of mine in the group whom I share the same dorm. Truthfully, we feel more comfortable with each other and do not mind socializing with others. On the other hand, some views were based on the team spirit and empathy such as I think having the sense of team spirit is beneficial because it creates a comfortable learning environment to accomplish the task together (P16/F). I give importance to show empathy for people around me because having the sense of empathy helps us understand the feelings of others and figure out their real feelings. Some participants alluded to the fact that groupwork has created a supportive and well-functioning environment in which students have social and emotional ties with each member and do not want to leave their peers in the lurch. For example, the participant coded P3/M quoted his feelings as, I feel pressure on me not to drop out of school. I know that I ' $m$ 
accountable for my team work and I need to attend regularly in order not to put my peers trouble to take on my responsibilities or my workload.

As given in Figure 3, some emergent codes regarding the theme "psychological perspectives" were "Promoting students' self-confidence", "Helping students overcome shyness", "Improving sense of responsibility" and, "Providing less stressful study conditions". The associated codes were based on the views such as Sharing of responsibility makes me feel good psychologically and self-confident. If we know our responsibilities, we come together as a group and we can tackle the tasks together (P63/M) and, I know being shy is my natural personality trait but I feel less discouraged when taking part in groupwork and I can express myself without fear of judgment or embarrassment (P37/M). Additionally, some participants pointed out groupwork to be less stressful. Working with group is less stressful and fun because of being low workload per person (P45/M). When we have groupwork, we work together to get work done quickly and well with minimum stress on anyone member of the group $(\mathrm{P} 2 / \mathrm{F})$.

\subsubsection{Findings Related to the Challenges of LATD on Groupwork}

The second model for the thematic aspect of the study included the challenges of LATD on groupwork. Related themes, namely, academic, social and psychological perspectives are shown in Figure 4. As illustrated in Figure 4, twelve codes were generated and categorized into the "academic perspectives" theme. Some emerging codes from the views and collected under this theme were "Affecting too much conflict's group dynamic and academic achievement", "Increasing the burden of work for some successful students", "Being unfair to get a low grade because of others" and, "Not splitting up the workload equally". One participant (P37/M) stated, The presence of conflicts in the group not only invites negativity but also causes polarization amongst peers in the group. Moreover, conflicts not overcome may be resulted in low academic achievement for the group members. Most participants complained that while some in the group were pulling the heaviest load and contributing to all tasks actively, some never wanted to assume full responsibility and to do much of the work in the group due to unbalanced work distribution. Some related quotations are as follows: There is always someone who doesn't care about doing accurate work (P64/F). It was disappointing to know that my grades brought down because of the peers in my group who did not do work at all (P16/F). I felt overlooked and unappreciated because of being shy around others who were more active and allowed to do more work than me (P55/M).

Some highlighting codes regarding the challenges of groupwork within the theme "social perspectives" are as follows: "Sometimes too much arrogance and overconfidence of leaders in the group", "the tendency of group members hanging around, gossiping or loafing around without doing their tasks", "Weakening of friendship relations due to clash of ideas" and, "Being reflected the negativity lived in the group in the normal life". The expressions related to the leader and leadership skills revealed as, Frankly, our team leader was fair and creative, additionally, he was experienced and knowledgeable enough to motivate us in groupwork (P9/F) and I would like to work with a humble and fair group leader. However, some display bossy and arrogant behaviours rather than gathering group members around him /her and respecting their ideas (P12/F). Some views expressed regarding being someone who doesn't take part groupwork effectively can be represented as, I got angry when one person in the group did not pull his/ her own weigh and left the work to others as extra work (P5/M) and While one person in the group is doing all of the work, some have the tendency to observe rather than act or the tendency to loaf due to having a partner to complete a task $(\mathrm{P} 43 / \mathrm{F})$. The views expressed by $\mathrm{P} 32 / \mathrm{M}$ were based on conflict and negativity between peer group members such as, I broke up with my best friend in the group for some reason, thereafter, more dangerous conflicts causing resentment and hostility happened between us that we reflected on other group members.

On the other hand, fifteen codes were generated with regard to the theme "psychological perspectives" taking part under the category "the challenges of LATD on groupwork". Some prominent codes are "Jealousy amongst the members of the group", "Blaming others for failure" and, "Getting disappointed quickly". The views of the participant coded (P58/M) were based on the jealousy such as, I saw how jealousy could be a problem in some groups. Some are jealous of teammates who are able to be skilful enough to manage the tasks in the groupwork. However, I clearly believe that I haven't witnessed jealousy with my group. The peers on my team are concerned with performance and productivity rather than showing off since we're a collaborative group, and we work together. Another participant coded (P17/M) expressed his views on blaming others for failures and continued, When encountering a problem, saying that it's not my fault and blaming others for failures without identifying who was involved in the problem will lead to work in an unsafe environment. The views expressed by $\mathrm{P} 21 / \mathrm{M}$ and $\mathrm{P} 52 / \mathrm{F}$ on disappointment were as follows: I struggle with disappointment in the group stemming from diverse reasons but especially when the fast result is not reached. Obviously, we have emotions as human being. When our emotions are shaken, we deal with them differently. Disappointment is also an emotion that we have to cope with appropriately as an individual or all group members to overcome in the group and try to get over it quickly for group productivity. 


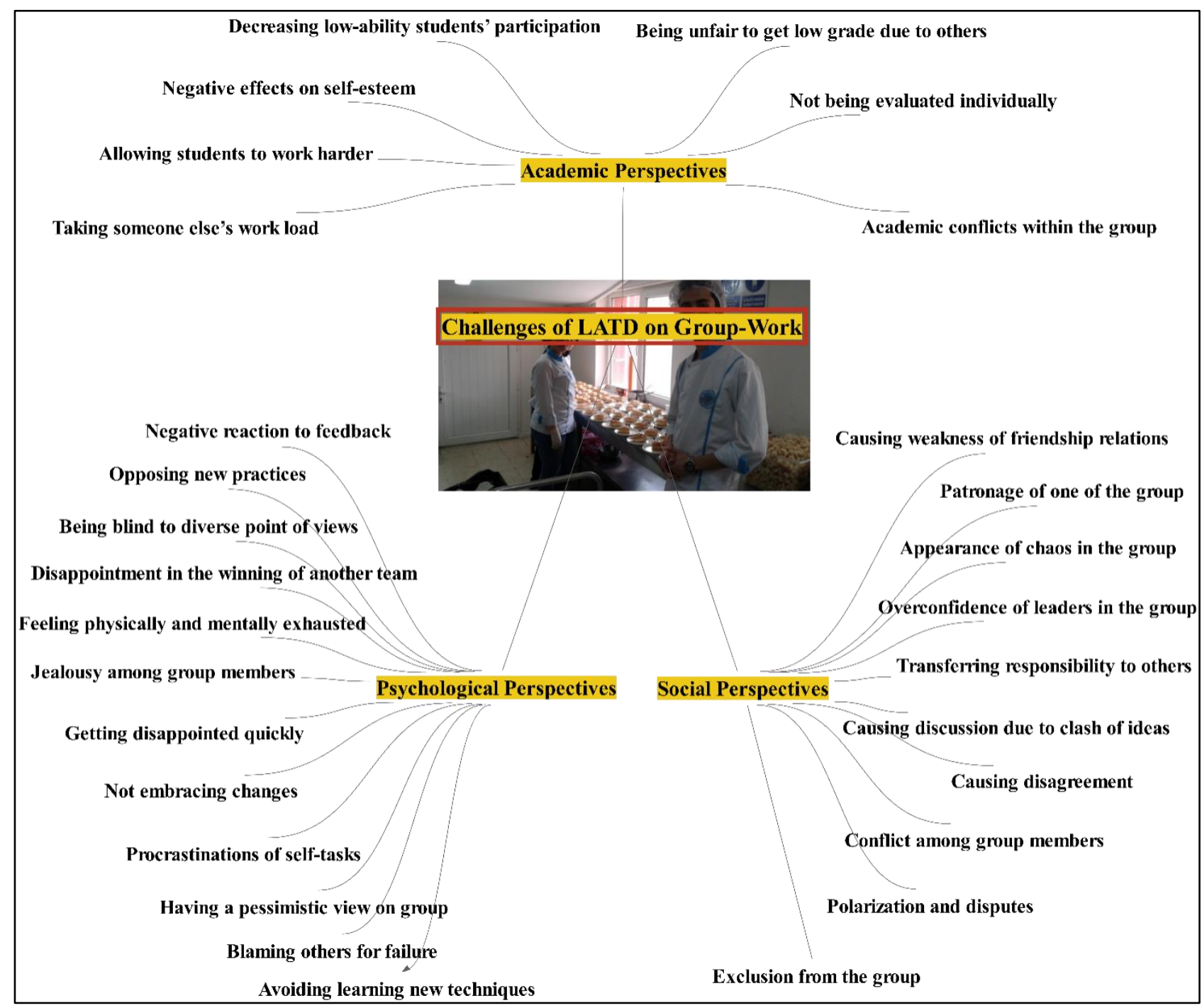

Fig. 4 - Challenges of LATD on groupwork in terms of academic, social and psychological perspectives

\section{Results}

This study was conducted to reveal the effect of the LATD on groupwork in a collaborative learning environment from different angles in line with methodological pluralism. In this regard, the Rasch analysis revealed that the students graduating from tourism or cooking related vocational high schools and having work experience in each group got higher scores than did their counterparts who did not graduate from tourism related high schools and had no work experience beforehand. In the evaluation of the high school graduation variable through the SPSS analysis, although there were no statistically significant differences among schools $\left(\mathrm{KWH}_{4}=3.046 ; p>.05\right)$, the highest arithmetic mean was found at Tourism Vocational High School and the lowest was at Regular High School (See Appendix 1).

The item difficulty analysis of the LATD scale revealed that while the most difficult item in the scale was the items coded I-9 -I can be interested in improbable approaches while thinking, the easiest item was the item coded I-1 I'm clever at innovation. This result is consistent with the findings of the SPSS analysis results conducted within the scope of methodological pluralism to reveal the arithmetic means of the nine items regarding LATD. Similarly, in the SPSS analysis, while the item coded I-1 has one of the highest arithmetic mean scores $(\bar{x}=3.84 ; S D=.818)$, the item I-9 has the lowest arithmetic mean score $(\bar{x}=3.26 ; S D=1.38)$. On the other hand, in the evaluation of the infit and outfit statistical values of the items of the LATD scale, no data exceeded from the determined limit values and this result indicated that there was a consistency with almost all the items of the scale used in the evaluation of LATD. In this regard, index values of the items were similarly found to be within the determined limits in the studies conducted by Batd1 and Elald1 (2016) and Batd1 (2017). According to Semerci (2011), in the studies conducted by using the Rasch model, additional measurement tools and methods should be processed to reveal the causes of biased results. Since, in order to obtain a better understanding, the use of different methods or techniques and comparing one set of results with another can 
enhance not only the validity of inferences (Creswell \& Plano Clark, 2011) but also the reliability of the study's results (Patton, 2002).

Based on this view, in order to maximize the scientific yield and the reliability of the results, this research was also supported with SPSS analysis and thematic analysis and the results of each analysis showed consistency with each other.

The students' perceptions regarding the effect of LATD on groupwork were obtained through thematic analysis in the qualitative phase of the study to support and combine the data of the quantitative phase within the frame of methodological pluralism. Two models with the titles of "advantages of LATD on groupwork" and "challenges of LATD on groupwork" were identified. The themes for the both models were generated as academic, social and psychological perspectives. Twenty-nine codes emerged for the theme academic perspectives under the title of "advantages of LATD on groupwork". The codes such as "Providing learning from peers in a group", "Contributing to peer learning or teaching" "The effect of positive bond among the group members on academic achievement", "Ensuring everyone's learning", "Carrying out individual responsibilities of the whole group", "Brainstorming for the group interaction" and, "Allowing both individual and group development to be assessed" were related to benefits gained from the group interaction. The results associated with the group interaction show similarities to the studies carried out Leopold and Smith (2019) and Unin and Bearing (2016). These studies have remarked peer learning as an essential prerequisite for one's cognitive development and implied that through interactions, students develop connections with their peers, learn to balance their interests with those of others, and through peer group influence, they develop confidence in their abilities. Astin (1993) pointed out that during the undergraduate years of a student, his/her peer group is the "single most potent source of influence on growth and development" (p.398). On the other hand, university students' interactions with their peers also have a strong effect on their intellectual development, academic success, general maturity and personal development (Alshammari, 2015; Hua, 2014). Furthermore, the study conducted by Hadzhikoleva, Hadzhikolev, and Kasakliev (2019) carried out similar results to the current study in terms of the views of the students regarding peer learning and its positive effect on assessment. They highlighted that peer assessment developed students' critical thinking skills and enhanced their understanding of assessment standards.

Regarding the advantage of the LATD on groupwork from "Social perspectives", the study revealed from the views of the participants that face to face interaction has increased positive connections among students and promoted each other's success due to being students' more enthusiastic about taking collective responsibility for their own and one another's learning. Similar results have been confirmed in the research focusing groupwork and its effect on social and communication skills and indicating that groupwork promotes an increase in learning interest, trust and mutual respect in others, and an increase in individual and collective responsibility (Chang \& Brickman, 2018; Lavasani, Afzali \& Afzali, 2011; Wilson, Ho, \& Rowan, 2018). Pillemer and Rothbard (2018) found friendship collaborations to have more intense and effective social activity depending on mutual liking, closeness, and loyalty. On the other hand, another result was associated with regular school attendance. In this regard, Rumberger (2004) has pointed out that social ties among students help them enjoy coming to school, and therefore, improve regular attendance and reduce the overall dropout rate.

From the "Psychological perspectives, the prominent views were "increasing in confidence", "emotional support", "creating positive synergy for liking partners or subject area", "having positive feelings toward group members", "an increase in group members' friendships and contacts both outside of the team and outside of the school", "bonding with each other and becoming committed to each other's well-being". In this context, if team members like and have positive feelings toward each other, they will be more likely to put forth their best effort (Prewett, Brown, Christiansen, \& Goswami, 2017). Additionally, the results regarding positive synergy existing in the team and its effects on improvements in self-esteem, liking partners or subject area were consistent with previous research that has indicated through positive synergy among all group members, peers tend to have a positive orientation towards each other's ideas, and are reluctant to criticize each other, especially in front of others (Chang \& Brickman, 2018; Ginsburg-Block, Rohrbeck, \& Fantuzzo, 2006).

Challenges of LATD on groupwork were identified under the themes of academic, social and psychological perspectives, as well. Some prominent codes obtained from the participants' views regarding academic challenges were "Being obliged to take on someone else's work load in the group", "Affecting too much conflict's group dynamic and academic achievement", "Slowing the pace of high-ability students' learning", "Increasing the burden of work for some successful students" and "Arising contradictions when thoughts and outcomes obtained are inconsistent with each other". These emerging codes showed consistency with previous research (e.g., Burdett, 2003; Roberts \& McInnerney, 2007) which revealed that the workload was not shared fairly, and therefore, due to one or more students' doing little or no work in the group, the group did not reach its full potential. According to Burdett (2003), owing to the nature of groupwork, it generally falls to one or two students to do the bulk of the work and it is an ongoing problem. In the shed of literature, it appears that for a number of students, groupwork can be an unpleasant and preferably avoidable component of study on account of free riding effect which is probably the most commonly cited negative effect of groupwork and illustrated as a behaviour pattern wherein an individual does little or no work in a group setting and fails to contribute almost nothing to the well-being of the group (Aggarwal \& O'Brien, 2008; Bacon, 2005; Burdett, 2003; Hall \& Buzwell, 2012; Jeroen Janssen \& Wubbels , 2018; Piezon, 2011). 
Among the codes related to the theme "Social challenges", the most considerable ones were "Conflict among group members", "Attempting to someone's in the group about leadership" and "Polarization and disputes". These results are in line with the evidence that many students dislike groupwork largely due to the interpersonal conflicts that can arise among group members (Hall \& Buzwell, 2012). In the same direction, Goncalo and Staw (2006) claimed that an individualistic-focused society, there is always going to be resistance from students toward groupwork, particularly when grades are involved. In this regard, by focusing on what people want in their group, Chun and Choi (2014) investigated three types of intragroup conflict as achievement and task conflict, affiliation and relationship conflict and power and status conflict and their effects on group performance. They found that while task conflict was a positive predictor of group performance, relationship and status conflicts were not significant predictors. On the other hand, due to the possibility of some individuals displaying inappropriate communication behaviour and tending to create turmoil in the group, confronting these difficult students may also lead to group conflicts that can become destructive and divide the group (Hadad \& Reed, 2007). Furthermore, although the findings of this study revealed the traits of group leaders such as fairness and creativity as motivating factors for groupwork, Hanke (2006), who has not supported creativity in a team leader, implies that a creative leader may undermine creative activity in a team because once a team has a solution it considers creative, the team no longer engages in creative activity.

Regarding the theme "Psychological challenges", the participants" views were captured in some codes such as "Being difficult to know all students' personal reaction in a team", "Jealousy amongst group members", "Blaming others for failure". Similarly, in the study conducted by Näykki, Järvelä, Kirschner and Järvenoja (2014), almost the same challenges emerging in this research such as jealousy in a group, need to please someone, and problems stemming from personal traits have taken part in the category of the socio-emotional challenges.

\section{Implications}

This study has aimed to provide more comprehensive and reliable results regarding the effect of LATD on groupwork in a collaborative learning environment by enriching the methodology with a combination of Rasch analysis, statistical analysis and thematic analysis in the scope of methodological pluralism. The quantitative findings of the current research revealed that the LATD of the students graduating from tourism or cooking related vocational high schools and having work experience were higher than their counterparts who did not graduate from tourism related high schools and had no work experience beforehand. The results indicate that the students in the two groups, who are engaged in their first year of university, tend to follow experienced persons' ideas rather than stimulating and developing their own creativity. Similarly, Hanke (2006) has implied that younger students, who have not yet been fully aware of the importance of creativity at the beginning of their university education, may be more interested in finding easy ways to get through a course rather than developing creativity or creative outputs and furthermore, they may also think that once creative ideas have been found the team's tasks are done. In other words, the more the individual's ideas are followed, the lower the level of creative activity within the team.

The qualitative results showed consistency with the quantitative results. For example, the codes emerging from the participants' views such as "Being open to innovations for the benefit of the group", "Brainstorming for alternative solutions", and "Providing different perspectives with mutual interaction" were in line with the scale items. Consequently, some implications of these findings are that students' prior knowledge and experiences are effective in reflecting their LATD into groupwork. In this regard, in the studies carried out by Burgh (2016), Hanke (2006), and Mustofa and Hidayah (2020), lateral thinking was found to be significantly related to aggregated individual creativity and positively related to the creative outputs of the team by indicating that it might be more accurate to consider lateral thinking at the individual level, because the creativity processes of individuals in a team affect the creative outputs of the team much more than the interactions among those team members. However, Csikzentmihalyi (as cited in Feldman, Csikzenmihayli \& Gardner, 1995) believes that individuals have opportunities to realize their creative potentials within supportive social framework, and therefore, when studying creativity, dealing with the individual alone is like "studying how an apple tree produces its fruit by only looking at the tree and ignoring the sun and the soil” (p.147).

Another implication is that both positive effects and challenges of groupwork have been dealt with from the students' perspective. Therefore, this study suggest that future research should examine the implications of LATD on groupwork not only from the students' perspective but also from the instructors' perspective to reveal whether there is consistency or not between the perspectives and to reveal expectations of both sides regarding the reflection of LATD on groupwork. This study also suggests that teachers should be trained so that lateral thinking skills can be implemented in class environment.

\section{Acknowledgement}

Special thanks to all personals and individuals who involves in this research. 


\section{References}

Alshammari, N. M. (2015). Effects of cooperative learning on academic performance of college students in Saudi Arabia (Master's Thesis). State University of New York, USA

Astin, A. (1993). What matters in college? Four critical years revisited. San Francisco: Jossey-Bass

Aud, S., Hussar, W., Kena, G., Bianco, K., Frohlich, L., Tahan, K. (2011). The condition of education 2011 (NCES 2011 033). Washington, DC: U.S. Department of Education, National Centre for Education Statistics

Bacon, D.R. (2005). The effects of group projects on content-related learning, Journal of Management Education, 29, 248-267

Barkley, E. F., Major, C. H., \& Cross, K. P. (2014). Collaborative learning techniques: A resource for college faculty. 2nd Edition. San Francisco, CA: Jossey-Bass

Batd1, V. (2017). Comparing the high school English curriculum in Turkey through multi-analysis, Kuram ve Uygulamada Eğitim Bilimleri, 17(4), 1127-1162. Doi: 10.12738/estp.2017.4.0490

Batd1, V. \& Elaldı, Ş. (2016). Analysis of high school German textbooks through Rasch Measurement Model. Journal of Education and Training Studies, 4(7), 61- 69. Doi: :10.11114/jets.v4i7.1455

Berber, N., Slavić, A., \& Aleksić, M. (2020). Relationship between perceived teamwork effectiveness and team performance in banking sector of Serbia. Sustainability, 12, 8753- 8768. Doi:10.3390/su12208753

Braun, V. \& Clarke, V. (2006). Using thematic analysis in psychology. Qualitative Research in Psychology, 3 (2), $77-$ 101

Burdett, J. (2003). Making groups work: University students' perceptions. International Education Journal, 4(3), 177191

Burgh, G. (2016). Creative and lateral thinking: Edward de Bono. In D. C. Phillips (Ed.), Encyclopedia of educational theory and philosophy (pp. 187-188). Thousand Oakes, CA: Sage. Doi:10.4135/9781483346229.n86

Chang, Y., \& Brickman, P. (2018). When group work doesn't work: Insights from students. CBE-Life Sciences Education, 17 (3), ar52, 1-17. Doi: 10.1187/cbe.17-09-0199

Choy, S. P. (2002). Findings from the condition of education 2002: Non-traditional undergraduates (NCES 2002-012). Washington, DC: U.S. Department of Education, National Centre for Educational Statistics

Chun, J. S., \& Choi, J. N. (2014). Members' needs, intragroup conflict, and group performance. Journal of Applied Psychology, 99(3), 437-450. http://dx.doi.org/10.1037/a0036363

Cohen, J. (1960) A coefficient of agreement for nominal scales. Educational and Psychological Measurement, 20, $37-$ 46. http://dx.doi.org/10.1177/001316446002000104

Creswell, J. (2003). Research design: Qualitative, quantitative and mixed methods approaches (2nd ed.). Thousand Oaks, CA: SAGE Publications

Creswell, J. W., \& Plano Clark, V. L. (2011). Designing and conducting mixed methods research (2nd ed.). Thousand Oaks, CA: Sage

Creswell, J. W., Plano Clark, V. L., Gutmann, M. L., \& Hanson, W. E. (2003). Advanced mixed methods research designs. In A.Tashakkori \& C.Teddlie (Eds.), Handbook of mixed methods in social and behavioural research (pp. 209240). Thousand Oaks, CA: Sage

Csikszentmihalyi, M. (1996). Creativity. New York: Harper Collins

Darling-Hammond, L., Flook,L., Cook-Harvey, C., Barron, B., \& Osher, D. (2020). Implications for educational practice of the science of learning and development. Applied Developmental Science, 24(2), 97-140. Doi: $10.1080 / 10888691.2018 .1537791$

Davidson, N., Major, C. H., \& Michaelsen, L. K. (2014). Small-group learning in higher education cooperative, collaborative, problem-based, and team-based learning: an introduction by the guest editors. Journal on Excellence in College Teaching, 25(3\&4), 1-6

De Bono, E. (1967). The five-day course in thinking. New York: Basic books

De Bono, E. (1969). The mechanism of mind. New York: Simon \& Schuster

De Bono, E. (1970). Lateral thinking: Creativity step by step. New York: Harper \& Row 
De Bono, E. (1971). Lateral thinking for management: A handbook for creativity. England: The President's Association

De Bono, E. (1991).Teaching thinking. Harmondsworth Middlesex, England: Penguin Books

De Bono, E. (1993). Serious creativity: Using the power of lateral thinking to create new ideas. USA: Harper Business

Driskell, J. E.,Salas, E.,\& Driskell, T. (2018). Foundations of teamwork and collaboration. American Psychologist Journal, 73, 334-348

Eanes, Z. (2018, July 10). For-profit school operator closing 30 campuses, including 3 in NC. The News \& Observer. Retrieved from https://www.newsobserver.com/news/local/article214193329.html

Edens, D. (2011). Predictors of culinary student satisfaction with learning. Journal of Hospitality \& Tourism Education, 23(3), 5-15. Doi:10.1080/10963758.2011.10697008

Embretson, S.E., \& Reise, S.P. (2000). Item Response Theory for Psychologists. Mahwah, NJ: Erlbaum

Feldman, D. Csikzenmihayli, M. and Gardner, H. (1995). Changing the world: A framework for the study of creativity. USA: Praeger

Gibson, D., Irving, L., \& Seifert, T. (2018). Assessing personal learning in online collaborative problem solving. In M. Shonfeld \& D. Gibson (Eds.), Collaborative learning in a global world (p. 450). Charlotte, NC: Information Age Publishers

Ginsburg-Block, M. D., Rohrbeck, C. A., \& Fantuzzo, J. W. (2006). A meta-analytic review of social, self-concept, and behavioral outcomes of peer-assisted learning. Journal of Educational Psychology, 98(4), 732-749

Glaveanu, V. P. (2010). Principles fora cultural psychology of creativity. Culture \& Psychology, 16, 147-163

Goncalo, J. A., \& Staw, B. M. (2006). Individualism-collectivism and group creativity. Organizational Behavior and Human Decision Processes, 100(1), 96-109

Hadad, M. \& Reed, M.J. (2007). The post-secondary learning experience. Toronto, ON: Thomson-Nelson

Hadzhikoleva, S., Hadzhikolev, E., \& Kasakliev, N. (2019). Using peer assessment to enhance higher order thinking skills. TEM Journal, 8(1), 242-247. https://doi.org/10.18421/TEM81-34

Hall, D. \& Buzwell, S. (2012). The problem of free-riding in group projects: looking beyond social loafing as reason for non-contribution. Active Learn High Education, 14, 37-49

Hanke, R. C. M. (2006). Team creativity: A process model. (PhD Dissertation). The Pennsylvania State University, USA

Haiyang, S. (2010). An application of classical test theory and many facet Rasch measurement in analyzing the reliability of an English test for non-English major graduates. Chinese Journal of Applied Linguistics, 33(2), 87-102

Hertzman, J. \& Mass, J. (2012). The value of culinary education: Evaluating educational costs, job placement outcomes, and satisfaction with value of associate degree culinary and baking arts program graduates. Journal of Culinary Science \& Technology, 10, 53-74

Hua, N. (2014). A feasible study on cooperative learning in large class college English teaching. Theory \& Practice in Language Studies, 4(9), 1862-1868

Ibrahim, B. B., Mohamad, N. H. B., Aziz, A. B. A., Kadir, M. B., Hamid, Z. B. A. (2020). A look at grit: A study about malaysian technical instructors' performance retention. International Journal of Innovation, Creativity and Change, $11(12), 620-636$

Jeroen Janssen, H. L. \& Wubbels, T. (2018) Collaborative learning practices: teacher and student perceived obstacles to effective student collaboration. Cambridge Journal of Education, 48(1), 103-122. Doi: 10.1080/0305764X.2016.1259389

John, E. B., \& Meera, K.P. (2014). Effect of cooperative learning strategy on the creative thinking skills of secondary school students of Kozhikode District. IOSR Journal of Humanities and Social Science (IOSR-JHSS), 19 (11), $70-74$

Johnson, D. W., \& Johnson, R. T. (2009). An educational psychology success story: Social interdependence theory and cooperative learning. Educational Researcher, 38(5), 365-379. Doi:10.3102/0013189X09339057

Johnston, J., \& Baumann, S. (2015). Foodies. Democracy and Distinction in the Gourmet Foodscape. (2nd edn) London: Routledge

Kagan, S. (1994). Cooperative learning. San Clemente, CA: Resources for Teachers, Inc 
Kaplan-Parsa, M. (2016). Effect of collaborative inquiry-based learning environment on creative thinking, inquiry learning skills, attitudes towards Science and Technology lesson (PhD Dissertation). Marmara University, İstanbul, Turkey

Karakaya, A. F. (2011). Collaborative environments to enhance creativity of design students: Use of collaborative creativity support tools (PhD Dissertation). Bilkent University, Ankara, Turkey

Kazanc1, K. (2014). The effect of Web tools 2.0 on critical thinking with a special emphasis on collaborative learning (PhD Dissertation). Çukurova University, Adana, Turkey

Korte, L. (2014). Collaborative and creative thinking skill development through the design of wearable technologies (PhD Dissertation). Walden University, Minneapolis, USA

Lavasani, M. G., Afzali, L., \& Afzali, F. (2011). Cooperative learning and social skills. Cypriot Journal of Educational Information \& Communication Technologies, 4, 186-193

Leeuwen, A. \& Jannsen, J. (2019). A systematic review of teacher guidance during collaborative learning in primary and secondary education. Educational Research Review, 27, 71-89

Leopold, H., \& Smith, A. (2019). Implementing reflective group work activities in a large chemistry lab to support collaborative learning. Education Science, 10(7), 1-19. Doi:10.3390/educsci10010007

Marks, M. A., Mathieu, J. E., \& Zaccaro, S. J. (2001). A temporally based framework and taxonomy of team processes. Academy of Management Review, 26, 356-376

Matzler, K., Uzelac, B., Bauer, F. (2014). Intuition's value for organizational innovativeness and why managers still refrain from using it. Management Decision, 52 (3), 526-539. https://doi.org/10.1108/MD-08-2013-0404

May, E. M., Hunter, B. A., \& Jason, L. A. (2017). Methodological pluralism and mixed methodology to strengthen community psychology research: an example from oxford house. Journal of community psychology, 45(1), 100-116. https://doi.org/10.1002/jcop.21838

McCreary, L. L., Conrad, K. M., Conrad, K. J., Scott, C. K., Funk, R. R., \& Dennis, M. L. (2013). Using the Rasch measurement model in psychometric analysis of the family effectiveness measure. Nursing Research, 62(3), 149-159

Milliken, F.J., Bartel, C.A., Kurtzberg, T.R. (2003). Diversity and creativity in work groups: A dynamic perspective on the affective and cognitive processes that link diversity and performance. In Paulus P.B. and Nijstad B.A. (eds), Group creativity: Innovation through collaboration (pp. 32-62). England: Oxford University Press

Moeller, B., \& Reitzes, T. (2011). Integrating technology with student-centred learning. The Education Development Centre, Inc. (EDC). Quincy, MA: Nellie Mae Education Foundation

Mohamad, N. H., Ibrahim, B., Selamat, A., Ismail, A., \& Kadir, Z. A. (2021). A Protocol for Development of HolisticEntrepreneur Graduates: Emotional Intelligence Perspectives. Journal of Technical Education and Training, 13 (1), $35-$ 43

Muriawa, S. (2015). Voluntary sampling design. International Journal of Advanced Research in Management and Social Sciences,4(2), 185-200

Mustofa, R. F., \& Hidayah, Y. R. (2020). The effect of problem-based learning on lateral thinking skills. International Journal of Instruction, 13 (1), 463-474. Doi: https://doi.org/10.29333/iji.2020.13130a

Müller, K., Van Leeuwen, D., Mandabach, K., \& Harrington, R. J. (2009). The effectiveness of culinary curricula: A case study. International Journal of Contemporary Hospitality Management, 21(2), 167-178

Naquin, C. E., \& Tynan, R. O. (2003). The team halo effect: Why teams are not blamed for their failures. Journal of Applied Psychology, 88, 332-340

Näykki, P., Järvelä,S., Kirschner, P., \& Järvenoja, H. (2014). Socio-emotional conflict in collaborative learning-A process-oriented case study in a higher education context. International Journal of Educational Research, 68, 1-14. Doi: 10.1016/j.ijer.2014.07.001

Nezami, N. R., Asgari, M., \& Dinarvand, H. (2013). The effect of cooperative learning on the critical thinking of High School students. Technical Journal of Engineering and Applied Sciences, 3(19), 2508-2514

North, B. (1993). The development of descriptors on scales of proficiency: Perspectives, problems, and a possible methodology. NFLC Occasional Paper. Washington, DC: National Foreign Language Centre 
Noguera, P., Darling-Hammond, L., \& Friedlaender, D. (2017). Equal opportunity for deeper learning. In R. Heller, R. Wolfe, \& A. Steinberg (Eds.), Rethinking readiness: Deeper learning for college, work, and life (pp. 81-104). Cambridge: Harvard Education Press

Okpara, O. F. (2007). The value of creativity and innovation in entrepreneurship. Journal of Asia Entrepreneurship and Sustainability, 3. Retrieved from http://www.asiaentrepreneurshipjournal.com/AJESIII2Okpara.pdf

Özdemir, S. (2005). The effects of individual and collaborative problem-based learning using an online asynchronized learning tool on critical thinking abilities, academic achievements, and attitudes toward internet use (PhD Dissertation). Gazi University, Ankara, Turkey.

Patton, M. Q. (2002). Qualitative research \& evaluation methods (3rd ed.). London: Sage Publications, Inc

Payne, G. (2006). Payne, G. (2006). Methodological pluralism. In Victor Jupp (Ed.), The Sage Dictionary of Social Research Methods (pp. 174-177). London: SAGE Publications Ltd

Piezon,S. L.(2011). Social loafing and free riding in online learning groups (PhD Dissertation). The Florida State University, USA

Pillemer, J., \& Rothbard, N. P. (2018). Friends without benefits: Understanding the dark sides of workplace friendship. The Academy of Management Review, 43(4), 635-660. https://doi.org/10.5465/amr.2016.0309

Prewett, M., Brown., M., Christiansen, N.D., \& Goswami, A. (2017). Effects of team personality composition on member performance: A multilevel perspective. Group \& Organization Management, 72, 1-33

Pun, S. K. (2012). Collaborative learning: A means to creative thinking in design. International Journal of Education and Information Technologies, 6(1), 33-43

Riding, A. (2006). Glimpses of a genius who blazed his paper trail. The New York Times, p. E1. Retrieved from https://www.nytimes.com/2006/09/26/arts/design/glimpses-of-a-genius-who-blazed-his-paper-trail.html

Roberts, T. S. \& McInnerney, J. M. (2007). Seven problems of online group learning (and their solutions). Educational Technology \& Society, 10(4), 257-268

Rumberger, R. W. (2004). Why students drop out of school. In G. Orfield (Ed.), Dropouts in America. Cambridge, MA: Harvard Education Press

Sawyer, J., \& Obeid, R. (2017). Cooperative and collaborative learning: Getting the best of both words. In R. Obeid, A. Schwartz, C. Shane-Simpson \& P. J. Brooks (Eds.), How we teach now: the GSTA guide to student-centred teaching (pp. 163-177). Washington, DC: Society of the Teaching of Psychology

Semerci, Ç. (2011). Mikro öğretim uygulamalarının çok yüzeyli Rasch ölçme modeli ile analizi [Analyzing microteaching applications with Many-facet Rasch Measurement Model]. Ë̆itim ve Bilim, 36(161), 14-25

Semerci, Ç. (2016). Developing a lateral thinking disposition (latd) scale: a validity and reliability study. Ĕgitimde Kuram ve Uygulama, 12(1), 358-371

Semerci, N. (2017). Pedagogical formation students' dispositions toward lateral thinking. Bartın Üniversitesi Ĕ̌itim Fakültesi Dergisi, 6(1), 336- 345. Doi: 10.14686/buefad.293271

Smith, E. V. (2000). Metric development and score reporting in Rasch measurement. Journal of Applied Measurement, $1(3), 303-326$

Tong, A., Sainsbury, P., \& Craig, J. (2007). Consolidated criteria for reporting qualitative research (COREQ): A 32-item checklist for interviews and focus groups. International Journal of Quality in Health Care, 19, 349-357. doi:10.1093/intqhc/mzm042

Traud, M. (2016). The connections between culinary education and the restaurant industry: A phenomenological investigation of educators', restaurant professionals' and recent graduates' views on culinary education (PhD Dissertation). Drexel University, Philadelphia, the USA

Trilling, B. \& Fadel, C. (2009). 21st Century Skills: Learning for Life in Our Times. Jossey-Bass, San Francisco, CA

Unin, N., \& Bearing, P. (2016, 6 15). Brainstorming as a way to approach student-cantered learning in the ESL Classroom. Procedia - Social and Behavioural Sciences, 224, 605-612

Uysal, M. E. (2009). The effects of cooperative learning method on the access, achievement, critical thinking and creativity skills of the elementary school fourth-grade students (PhD Dissertation). Dokuz Eylül University, İzmir, Turkey 
Vaughan J, Mallett, C.J., Davids, K., Potrac, P. \& López-Felip, M.A. (2019). Developing creativity to enhance human potential in sport: A Wicked transdisciplinary challenge. Frontiers in Psychology, 10, 2090. Retrieved from https://www.frontiersin.org/articles/10.3389/fpsyg.2019.02090/full?report=reader

Ware, S. (2020). How creativity and innovation enhance business growth and development. In Creativity in Business. Retrieved from https://truscribe.com/business-growth-with-creativity-and-innovation/

Wilson, L., Ho, S., \& Rowan, R. H. (2018). Student perceptions of teamwork within assessment tasks in undergraduate science degrees. Assessment \& Evaluation in Higher Education, 43(5), 786-799. Doi: 10.1080/02602938.2017.1409334

Wright, B. D., \& Linacre, J. M. (1994). Reasonable mean-square fit values. Transactions of the Rasch measurement SIG American Educational Research Association. Rasch Measurement Transaction, 8(3), 370-382

Yang, J. (2016). Thriving organizational sustainability through innovation: Incivility climate and teamwork. Sustainability, 8(9), 860-872. doi:10.3390/su8090860

Zhang, L. (2009). Engaging university learners in critical thinking to stimulate collaborative learning: Perceptions of American and Chinese students (PhD Dissertation). The University of South Dakota, USA

Zopiatis, A., Theodosiou, P., \& Constanti, P. (2014). Quality and satisfaction with culinary education: evidence from Cyprus. Journal of Hospitality \& Tourism Education, 26(2), 87-98

\section{Appendices}

\section{Appendix-1}

Table 7 - Kappa values obtained from the themes of the study

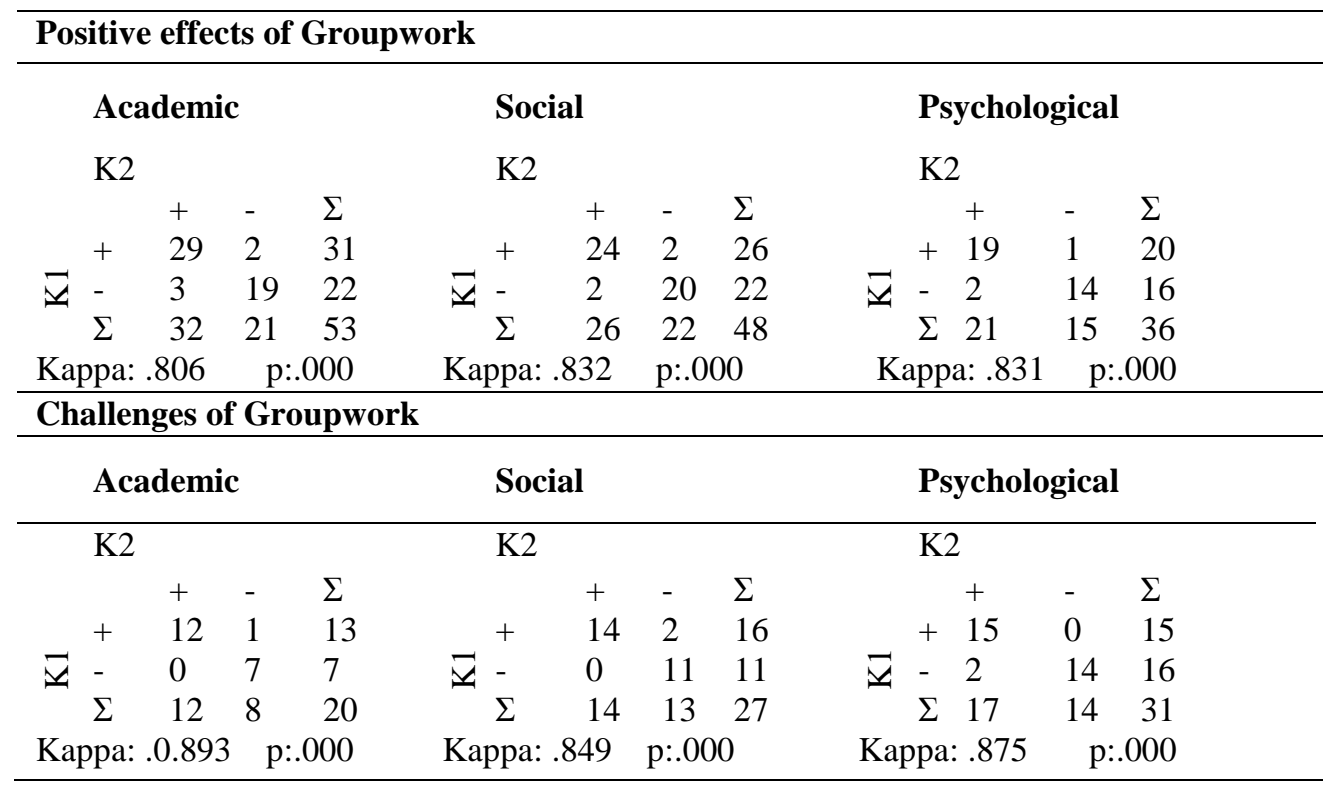

\section{Appendix-2}

Table 8 - Arithmetic means of the items 


\begin{tabular}{llll}
\hline $\begin{array}{l}\text { Item } \\
\text { Num. }\end{array}$ & ITEMS & Mean & SD \\
\hline 1 & I'm clever at innovation & 3.84 & .818 \\
2 & I tell different things to change one's mind. & 3.78 & 1.00 \\
3 & I have aims in my aim. & 3.84 & .993 \\
4 & I create alternative solutions against a problem. & 4.21 & .884 \\
5 & I don't follow only one way when thinking about a subject, I create new & 3.69 & .933 \\
& aspects. & 3.95 & .961 \\
6 & I look at very different aspects of the events & 3.50 & .915 \\
7 & I can brainstorm about all aspects of a subject & 3.42 & 1.07 \\
8 & I don't have fixed categorizations, classifications and & 3.26 & 1.38 \\
\hline
\end{tabular}

\section{Appendix-3}

Table 9 - Variance analysis results according to the graduated high school variable

\begin{tabular}{llllll} 
LATD Scale & & & & & \\
\hline Graduated High School & $\mathrm{N}$ & $\mathrm{M}$ & $\mathrm{SD}$ & $\mathrm{F}$ & $\mathrm{P}$ \\
\hline Tourism Vocational High School & 8 & 4.03 & .70 & & \\
Anatolian Hotel and Tourism High School & 11 & 3.83 & .71 & & \\
Anatolian Technical-Vocational High School & 23 & 4.00 & .81 & & \\
Anatolian High School & 25 & 3.73 & .65 & 1.039 & .380 \\
Regular High School & 16 & 3.68 & .92 & & \\
Total & 83 & 3.84 & .818 & & \\
\hline
\end{tabular}

\section{Appendix-4}

Table 10 - The level of LATD in terms of gender variable

\begin{tabular}{|c|c|c|c|c|c|c|c|}
\hline \multirow[b]{2}{*}{ Gender } & \multirow[b]{2}{*}{$\mathrm{n}$} & \multirow[b]{2}{*}{ Mean } & \multirow[b]{2}{*}{ SD } & \multicolumn{2}{|c|}{ Levene } & \multirow[b]{2}{*}{$\mathrm{t}$} & \multirow[b]{2}{*}{$\mathrm{p}$} \\
\hline & & & & $\mathrm{F}$ & $\mathrm{p}$ & & \\
\hline Male $(53 \%)$ & 44 & 3.95 & .888 & \multirow{3}{*}{.011} & \multirow{3}{*}{.915} & \multirow{3}{*}{1.320} & \multirow{3}{*}{.191} \\
\hline Female $(47 \%)$ & 39 & 3.71 & .723 & & & & \\
\hline Total & 83 & & & & & & \\
\hline
\end{tabular}

